\title{
Structural changes in the Czech, Slovak and euro area economies during the Great Recession Stanislav Tvrz, ${ }^{1}$ Osvald Vaší̌̌ek ${ }^{2}$
}

\begin{abstract}
The goal of this paper is to identify and compare the most important changes in the structure of the Czech economy, as a small open economy with independent monetary policy, the Slovak economy, as a small open economy that entered monetary union, and the economy of the euro area, which has a common monetary policy, during the turbulent period of the Great Recession, the subsequent anaemic recovery and recent disinflationary period. Structural changes are identified with the help of nonlinear dynamic stochastic models of general equilibrium with time-varying parameters. The model parameters are estimated using Bayesian methods and a nonlinear particle filter. The results confirm the similarity of the Czech and Slovak economies and show that in certain respects the structure of the Czech economy might be closer to that of the euro area than that of Slovakia. The time-varying estimates reveal many similarities between the parameter changes in the Czech economy and those in the euro area. In Slovakia, the situation during the Great Recession was dominated by the country's adoption of the euro, which caused large deviations in its Calvo parameters.
\end{abstract}

Key words: DSGE model, Great Recession, monetary union, time-varying parameters, particle filter

JEL Classification: E37, E44, F45

Received: 6 June 2016/ Accepted: 26 September 2016/ Sent for Publication: 9 November 2016

\section{Introduction}

While Slovakia entered the exchange rate mechanism ERM II shortly after becoming a member of the European Union, and adopted the euro currency in 2009, attitudes towards the euro in its neighbouring Czech Republic remained hesitant. The Czech National Bank's (CNB) exchange rate intervention in November 2013 (see Figure 1) showed that its independent monetary policy is not restricted to setting policy rates, especially in an environment of near-zero interest rates. The Czech central bank seems to be ready to use all available instruments to deliver further monetary easing consistent

\footnotetext{
${ }^{1}$ National Bank of Slovakia, Economic and Monetary Analyses Department, Imricha Karvaša 1, 81325 Bratislava; Masaryk University, Faculty of Economics and Administration, Lipová 41a, 60200 Brno; tvrz@mail.muni.cz, +421906122653, +421949110891, corresponding author

${ }^{2}$ Masaryk University, Faculty of Economics and Administration, Lipová 41a, 60200 Brno; osvald@econ.muni.cz
}

(c) 2016 by the authors; licensee Review of Economic Perspectives / Národohospodářský obzor, Masaryk University, Faculty of Economics and Administration, Brno, Czech Republic. This article is an open access article distributed under the terms and conditions of the Creative Commons Attribution 3.0 license, Attribution - Non Commercial - No Derivatives. 
with its inflation target. Three years after that intervention, inflation in the Czech economy remains far from its target, mainly because the inflation imported from the euro area is much lower than had been expected. The main goal of avoiding deflation has been achieved, although the downturn in oil prices weighed on consumer prices at the end of 2014 (see Figure 2).

\section{Figure 1 Nominal exchange rates}

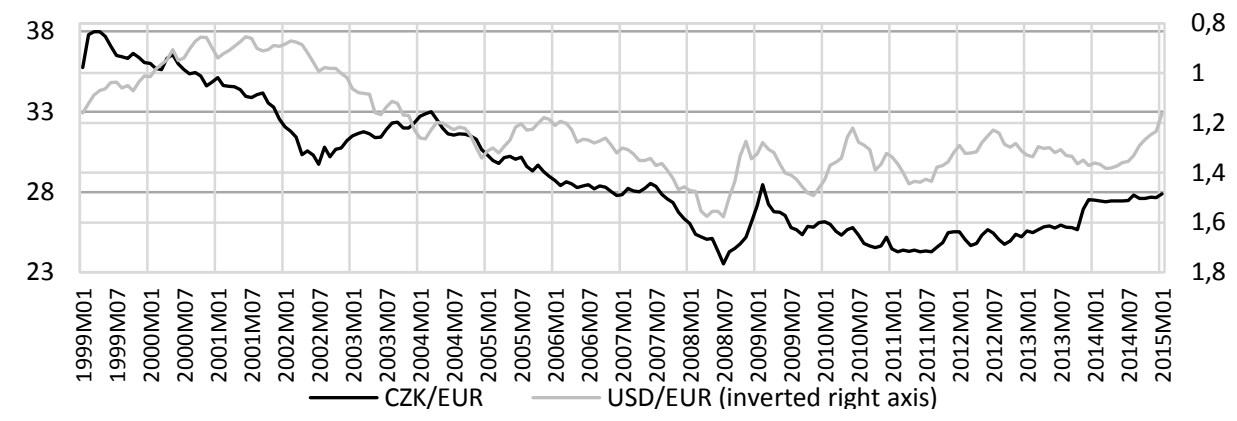

Source: European Central Bank.

As a member of the Eurosystem, the National Bank of Slovakia cannot make such an intervention alone; on the other hand, it participates in setting monetary policy for the whole euro area. Arguably, the Slovak economy benefited substantially from adopting the common European currency, especially immediately after its accession to the eurozone, when it recovered from the Great Recession much more quickly than the neighbouring Czech economy. ${ }^{3}$ Apart from differences in their monetary policy setup, the fiscal reaction to the Great Recession and subsequent debt crisis in the euro zone has led to further divergence in the economic development of these two Central European economies.

\section{Figure 2 HICP inflation (per cent, YoY)}
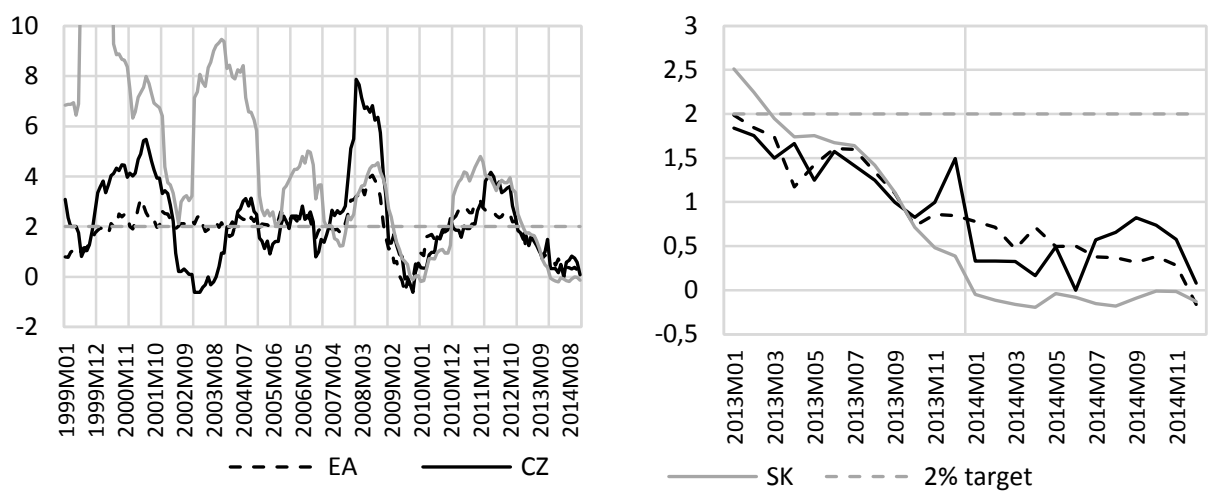

Source: Eurostat.

\footnotetext{
${ }^{3}$ According to Žúdel and Melioris (2016), the fact that Slovakia adopted the euro increased its GDP per capita by $10 \%$ between 2008 and 2011 .
} 
The situation in the eurozone is similar to that in the Czech Republic - the ECB declared its commitment to preventing deflation in the euro area using any means necessary. But because the euro currency holds a different position in the world economy, a CNB-style exchange rate intervention is not easily imaginable. In an environment of near-zero interest rates the ECB took the path of quantitative easing. At the same time, the ECB is appealing to the governments of eurozone countries to pursue necessary structural reforms.

Figure 3 depicts the lending margins ${ }^{4}$ of loans for house purchases and loans to nonfinancial corporations in the Czech, Slovak and German (as a principal member of the euro area) economies. We can distinguish a steep rise in the spread between the interest rate of loans for house purchase and the reference long term interest rate at the turn of 2008 and 2009. The spread between the interest rate of the loans to non-financial corporations gradually increased between 2008 and 2010 in the Czech and Slovak economies, while in Germany the spread increased sharply during the crisis and began to level off in 2010. Overall, interest rate spreads increased significantly during the eruption of the global economic crisis that induced the Great Recession. Banks perceived increased uncertainty and systemic risk in the economy and raised their required risk premium. As the central banks reacted to the prospect of a recession and the expected drop in inflation, the commercial banks' opportunity costs declined. However, this was not immediately reflected in client interest rates, and lending margins swelled. The observed behaviour of the commercial banks constitutes a financial friction because it led to a disruption of the link between the policy rates and the real economy. The increased delay in the transmission of monetary policy during the Great Recession is one of the main reasons why the zero lower bound was hit, which led to the need for alternative ways of delivering further easing of monetary conditions.

Figure 3 Lending margins (percentage points)
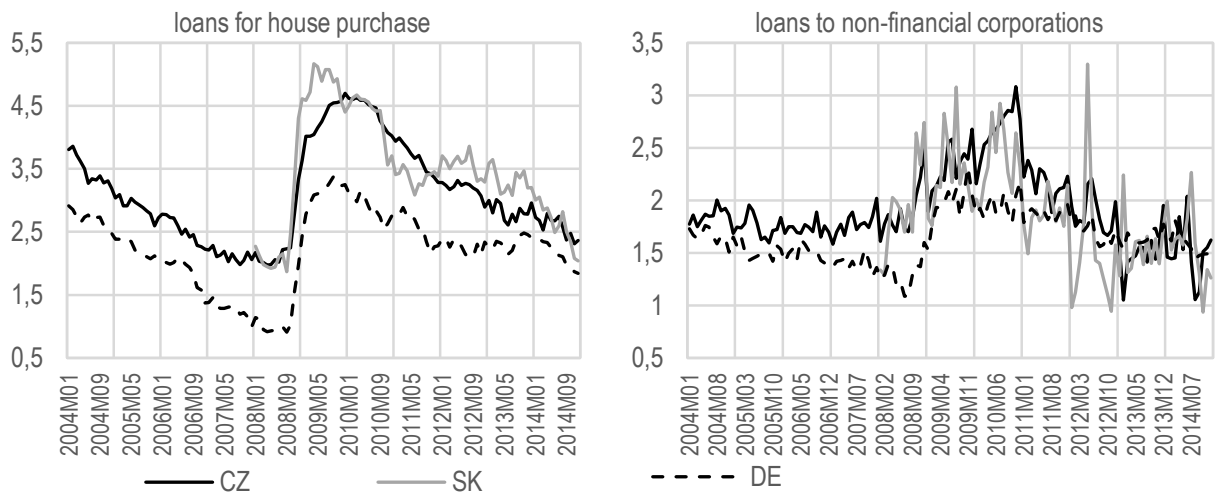

Source: European Central Bank.

4 According to the European Central Bank (2000), the lending margin is defined as "the difference between banks' average contractual rates on new loans (flows) and a reference rate. The reference rate is the market interest rate of a corresponding average maturity representing the financial opportunity cost for banks. It is not intended to represent the (marginal) cost of funds for the bank." 
The recent turbulent period of the Great Recession, therefore, brought about both visible structural changes - such as Slovakia joining the euro area, and institutional changes in the Eurosystem - and possibly unobserved structural changes (including the emergence of financial frictions). Conceivably, the characteristics of the behaviour of households, firms and/or monetary authorities might have temporarily or permanently changed due to the extraordinary events experienced. The goal of this paper is to identify and compare the most important changes in the structure of the Czech economy as a small open economy with an independent monetary policy, the Slovak economy as a small open economy that entered a monetary union, and the economy of the euro area, which has a common monetary policy, during the turbulent period of the Great Recession, the subsequent anaemic recovery and the recent disinflationary period. We want to find out which structural changes identified during the Great Recession are common to all three economies, and which are country-specific or dependent on the monetary policy regime. For this purpose, we estimate three DSGE models in total - a DSGE model of the Czech small open economy with its independent monetary policy, a DSGE model of the Slovak small open economy with a deterministic regime switch, which enables the transition from independent monetary policy to monetary union, and a DSGE model of the economy of the 17 euro area countries with their common monetary policy. Timevarying structural parameters are assumed in all the models, rendering them nonlinear. Filtration of the three models is performed with the use of a nonlinear particle filter (NPF) in order to identify the unobserved trajectories of time-varying parameters.

The results presented in this paper are the outcome of a line of research whose earlier results were published in Tvrz and Vašíček (2014), Tvrz and Vašíček (2015) and Tvrz (2014). A twin paper concerning the economies of the Czech Republic, Poland and Hungary was published as Tvrz and Vašíček (2016). In this paper, we elaborate on our previous research and present a comprehensive set of empirical results with the focus on the Czech and Slovak economies and the economy of the euro area. In comparison with our previous publications, this paper presents updated results estimated on longer time series. We have also reworked the implementation of the monetary policy regime switch in the case of Slovakia. The structural stability of the small Central European economies has been investigated for example by Vašíček et al. (2011), who found evidence of parameter drifting in the Czech data, and by Čapek (2012), who compared a recursive estimation approach to non-linear filtration. The structural stability of the Slovak economy has been less fully investigated. The structural differences between the Czech and Slovak labour markets were investigated in Němec (2013). The implications of financial frictions for monetary policy in the Czech small open economy were investigated in detail by Ryšánek et al. (2012).

The structure of this paper is as follows: section 2 describes the main features of the small open economy DSGE model used for the analysis; section 3 explains the basic principles of the estimation technique of the nonlinear particle filter; section 4 describes the input data, the data sources and preliminary transformations; section 5 contains the calibration; section 6 presents the empirical results together with their economic interpretation; section 7 sums up the paper's main findings. 


\section{Model}

Since we focus on the period of the financial, and subsequently economic, crisis, we use a DSGE model with financial frictions for our analysis. Specifically, we use the model framework developed by Shaari (2008), which incorporates the financial accelerator mechanism proposed by Bernanke et al. (1999) in the small open economy setting of Justiniano and Preston (2010). This tractable medium-sized model of a small open economy incorporates important real as well as nominal rigidities and enables us to describe the Czech and Slovak economies and the economy of the euro area in reasonable detail. The model structure was slightly altered for the case of Slovakia in order to allow a regime switch capturing its accession to monetary union. We also departed from the original model specification of Shaari (2008) in modelling the foreign variables as a SVAR(1) block, and we added an exogenous component to the development of entrepreneurial net worth, the net worth shock.

The model includes households, entrepreneurs, retailers, a central bank and the foreign sector. The households receive wages for the labour supplied; there are government transfers, profits made by retailers and domestic and foreign bond returns. Domestic bonds pay a fixed nominal return in domestic currency while foreign non-contingent bonds give a risk adjusted nominal return denominated in foreign currency. The debtelastic risk premium contains an exogenous $\mathrm{AR}(1)$ component of risk-premium or uncovered interest parity shock. The households then spend their earnings on consumption and domestic and foreign bond acquisition.

\subsection{Entrepreneurs}

Entrepreneurs play two important roles in the model. They run wholesale goods producing firms and they produce and own capital. The markets of intermediate goods and capital goods are assumed to be competitive. Wholesale goods production is affected by a domestic productivity AR(1) shock and capital goods production is subject to capital adjustment costs. Entrepreneurs finance the production and ownership of capital $K_{t}$ by their net-worth $N_{t}$ and borrowed funds. The cost of borrowed funds is influenced by the borrower's leverage ratio via an external finance premium

$$
E F P_{t}=\left(\frac{N_{t}}{Q_{t-1} K_{t}}\right)^{-\chi},
$$

where $Q_{t}$ is the real price of capital or Tobin's $\mathrm{Q}$ and $\chi$ is the financial accelerator parameter. To maximize profit, entrepreneurs choose the optimal level of capital and borrowed funds.

Over each period a proportion $\left(1-A_{t}^{N W}\right) \zeta$ of entrepreneurs leaves the market and their equity $\left(1-A_{t}^{N W}\right) \varsigma V_{t}$ is transferred to households in a form of transfers. $A_{t}^{N W}$ is a shock in entrepreneurial net worth. It influences the development of net worth by changing the entrepreneurs' bankruptcy rate, since its positive innovations increase the survival rate of entrepreneurs. Its logarithmic deviation from a steady state is assumed to evolve according to the $\mathrm{AR}(1)$ process. $\zeta$ is the steady-state bankruptcy rate. 


\subsection{Retailers}

There are two types of retailers in the model - home goods and foreign goods. Both are assumed to operate in conditions of monopolistic competition. Home goods retailers buy domestic intermediate goods at wholesale price and sell the final home goods to consumers. Foreign goods retailers buy goods from foreign producers at the wholesale price and resell them to domestic consumers. The difference between the foreign wholesale price expressed in domestic currency and the final foreign goods price, that is the deviation from the law of one price (LOP), is determined by an exogenous AR(1) shock. Nominal rigidities are introduced into the model by Calvo-type price setting and inflation indexation of retailers.

\subsection{Central bank}

The central bank determines the nominal interest rate in accordance with the following forward-looking Taylor interest rate rule (small letter variables denote deviations from steady state, which means a gap):

$$
i_{t}=\rho \cdot i_{t-1}+(1-\rho) \cdot\left[\beta_{\pi} \cdot E\left(\pi_{t+1}\right)+\Theta_{y} \cdot E\left(y_{t+1}\right)\right]+\varepsilon_{t}^{M P},
$$

where $i_{t}$ is the nominal policy interest rate gap, $\rho$ is a smoothing parameter, $\beta_{\pi}$ is the weight parameter of the expected inflation gap $E\left(\pi_{t+1}\right)$ and $\Theta_{y}$ is the weight parameter of the expected output gap $E\left(y_{t+1}\right)$. Deviations of the interest rate from the interest rate rule are interpreted as monetary policy i.i.d. shocks $\varepsilon_{t}^{M P}$.

\subsection{The foreign sector}

Following Christiano et al. (2011), the foreign economy variables - real output, consumer price index (CPI) inflation and nominal interest rate - are modelled using a structural SVAR(1) model as described in equation (3). The ordering of the foreign variables corresponds to a strategy for identifying the monetary policy shock, with the assumption that inflation and output are predetermined relative to it.

$$
\left(\begin{array}{c}
y_{t}^{*} \\
\pi_{t}^{*} \\
i_{t}^{*}
\end{array}\right)=\left(\begin{array}{lll}
\rho_{y^{*} y^{*}} & \rho_{y^{*} \pi^{*}} & \rho_{y^{*} i^{*}} \\
\rho_{\pi^{*} y^{*}} & \rho_{\pi^{*} \pi^{*}} & \rho_{\pi^{*} i^{*}} \\
\rho_{i^{*} y^{*}} & \rho_{i^{*} \pi^{*}} & \rho_{i^{*} i^{*}}
\end{array}\right)\left(\begin{array}{c}
y_{t-1}^{*} \\
\pi_{t-1}^{*} \\
i_{t-1}^{*}
\end{array}\right)+\left(\begin{array}{ccc}
1 & 0 & 0 \\
\sigma_{\pi^{*} y^{*}} & 1 & 0 \\
\sigma_{i^{*} y^{*}} & \sigma_{i^{*} \pi^{*}} & 1
\end{array}\right)\left(\begin{array}{c}
\varepsilon_{t}^{y^{*}} \\
\varepsilon_{t}^{\pi^{*}} \\
\varepsilon_{t}^{i^{*}}
\end{array}\right)
$$

\subsection{Regime switch}

In the case of the Slovak economy, the structure described above is relevant only to the period prior to its accession to the euro area, in other words until the end of 2008. An additional observable time series is included in the model to indicate the deterministic regime switch to monetary union at the beginning ${ }^{5}$ of 2009 . The regime switch changes two model equations, the Taylor rule and the uncovered interest parity (UIP) condition.

\footnotetext{
${ }^{5}$ The regime switch is executed in 2009Q1. Another possibility would be to place the regime switch at some point during the ERM II period; however, the exact point is unclear. It would also be possible to assume gradual phasing-in during the ERM II, i.e. an incremental transition instead of the 0/1 switch. However, due to the strong appreciation of the Slovak koruna in ERM II, which necessitated multiple central parity adjustments and different settings of the nominal interest rate
} 
The interest rate policy is decided outside the member economies of the monetary union. Due to the size of the Slovak economy and its share of the total euro area GDP, we can consider the nominal interest rate to be given exogenously. Therefore, the Taylor rule equation (2) is replaced by

$$
i_{t}=i_{t}^{*}
$$

The original forward-looking UIP condition (log-linear)

$$
r e r_{t+1}-\operatorname{rer}_{t}=\left(i_{t}-\pi_{t+1}\right)-\left(i_{t}^{*}-\pi_{t+1}^{*}\right)+\Psi_{B} \cdot z_{t}+a_{t}^{U I P}
$$

describes the development of the real exchange rate $\mathrm{rer}_{t}$ in terms of the real interest rate differential and the risk premium, which is a function of net foreign assets $z_{t}$ with elasticity $\Psi_{B}$ and contains an exogenous $\operatorname{AR}(1)$ component, the UIP shock. As in monetary union the nominal interest rates are equal by definition, the UIP equation simplifies to

$$
r e r_{t}-\operatorname{rer}_{t-1}=\pi_{t}^{*}-\pi_{t}+\Psi_{B} \cdot z_{t}+a_{t}^{U I P}
$$

and the development of the real exchange rate is mainly driven by the inflation differential. In order to resolve the transition from a situation when the central parity of an appreciating currency in a converging economy is set below the steady state (the domestic currency is too strong), we keep the risk premium component present in the UIP condition. ${ }^{6}$

The exchange rate of the Slovak koruna together with its central parity and \pm 15 percent fluctuation band is depicted in Figure 4. The central parity of the Slovak koruna was set to 38.4550 SKK/EUR in November 2005, when Slovakia entered the ERM II mechanism. It was then adjusted in March 2007 to 35.4424 SKK/EUR and further in May 2008 to 30.1260 SKK/EUR. The problem was that the strong appreciation of the Slovak koruna in this period was not only a manifestation of economic convergence, but also driven by the business cycle. In a floating exchange rate regime the Slovak koruna would probably have depreciated during late 2008 and early 2009, as the Czech currency did (see Figure 1). In retrospect, the second adjustment of the central parity to the value of the former lower bound in May 2008 probably resulted in the central parity being set below the steady state.

\footnotetext{
in Slovakia than in the euro area, we chose the approach described in the main text.

${ }^{6}$ It would also be possible to include the risk premium in the monetary policy rule instead. This would correspond to a situation with the common currency already in place and monetary policy would switch to an exchange rate targeting regime. This setting would correlate with the observed reality, where the availability of funds (foreign bonds) remains rather heterogeneous across the euro area countries. However, this approach does not deal with the adjustment of the real exchange rate from below the steady state after the adoption of the euro currency.
} 
Figure 4 The nominal exchange rate of Slovak koruna

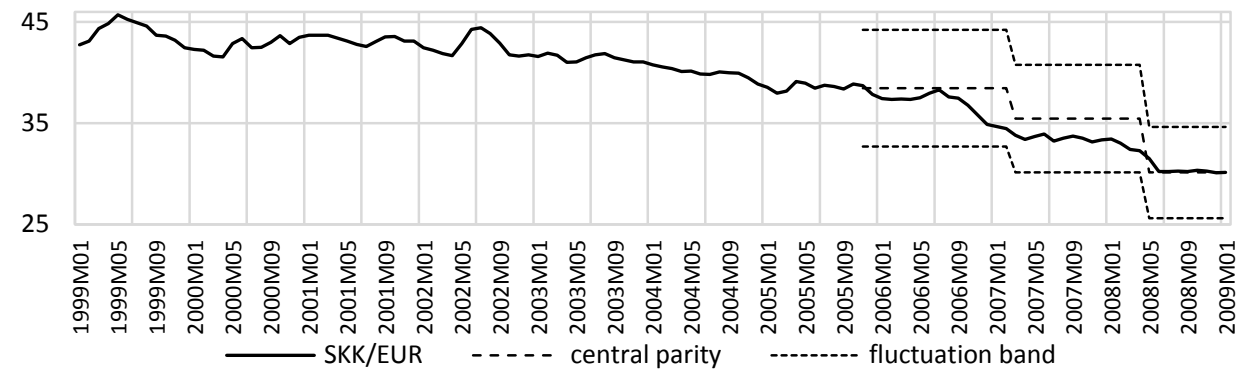

Source: European Central Bank.

\subsection{Time-varying parameters}

All the estimated model parameters are considered time-varying with the exception of the shock autoregression parameters and standard deviations. Time-varying parameters are defined as unobserved endogenous variables with the following law of motion

$$
\theta_{t}=\left(1-\alpha_{t}^{\theta}\right) \cdot \theta_{t-1}+\alpha_{t}^{\theta} \cdot \bar{\theta}+v_{t}^{\theta},
$$

where $\theta_{t}$ is a general time-varying parameter, $\bar{\theta}$ is the initial value of this parameter, $\alpha_{t}^{\theta}$ is the time-varying adhesion parameter common for all the remaining time-varying parameters and $v_{t}^{\theta} \sim N\left(0, \sigma_{v}^{\theta}\right)$ is exogenous innovation in the value of parameter $\theta_{t}$. Setting the adhesion parameter $\alpha_{t}^{\theta}$ influences the tendency of the time-varying parameter $\theta_{t}$ to return to its initial value $\bar{\theta}$. With $\alpha_{t}^{\theta}=0$, the time-varying parameter would be defined as a random walk, while with $\alpha_{t}^{\theta}=1$, the parameter would be white noise centered around the initial value $\bar{\theta}$. For the purposes of this paper, we set the initial value of the adhesion parameter to a value of $\alpha_{0}^{\theta}=0.25$. Since $\alpha_{t}^{\theta}$ is itself considered to be time-varying, its adhesion parameter is set to a fixed value of 0.01 . The adhesion parameter is therefore virtually free to drift away from its initial value. The choice of the calibration of adhesion parameter $\alpha_{0}^{\theta}$ does not qualitatively change the results. A sensitivity analysis was performed with the value of this parameter set to $0.01,0.05,0.10,0.25$ and 0.50 . The persistence of the identified trajectories of the timevarying parameters is larger for the lower values of adhesion. However, the main characteristics of the development identified (such as the direction and timing of major shifts in the values of given parameters) remain more or less the same.

\section{Estimation technique}

A nonlinear particle filter (NPF) is used in this paper to identify the unobserved states of the DSGE model, including the time-varying parameters. In this section we briefly describe the main principles of this nonlinear particle filter.

\subsection{Nonlinear particle filter}

Unlike a basic Kalman filter, which is only optimal for linear systems with Gaussian noise, the nonlinear particle filter is a more sophisticated tool that can be used even for 
nonlinear state-space systems with non-Gaussian noise. In this section, we provide only the basic principles of the algorithm. A detailed description can be found for example in Haug (2005).

Figure 5 contains a diagram of the NPF algorithm. In condensed form, the NPF algorithm can be described as follows:

1. Initialization: $t=0$, set the prior mean $\bar{x}_{0}$ (steady state) and covariance matrix $P_{0}$ for the state vector $x_{t}$.

2. Generating particles: Draw a total of $N$ particles $x_{t}^{(i)}, i=1, \ldots, N$ from distribution $p\left(x_{t}\right)$ with mean $\bar{x}_{t}$ and covariance matrix $P_{t}$.

3. Time Update: $t=t+1$, for each particle $(i=1, \ldots, N)$ propagate the particle into the future with the use of nonlinear transition and measurement equation and calculate means $\bar{x}_{(t \mid t-1)}, \bar{y}_{(t \mid t-1)}$ and covariance matrices $P_{(t \mid t-1)}, P_{(y \mid y)}$, $P_{(x \mid y)}$.

4. Kalman filter: Calculate Kalman gain $K_{t}=P_{(x \mid y)}\left(P_{(y \mid y)}\right)^{-1}, \bar{x}_{t}=\bar{x}_{(t \mid t-1)}+$ $K_{t}\left(y_{t}-\bar{y}_{(t \mid t-1)}\right)$ and $P_{t}=P_{(t \mid t-1)}-K_{t} P_{(y \mid y)}\left(K_{t}\right)^{T}$.

5. Continue step II until $t=t_{\max }$.

Figure 5 Nonlinear particle filter

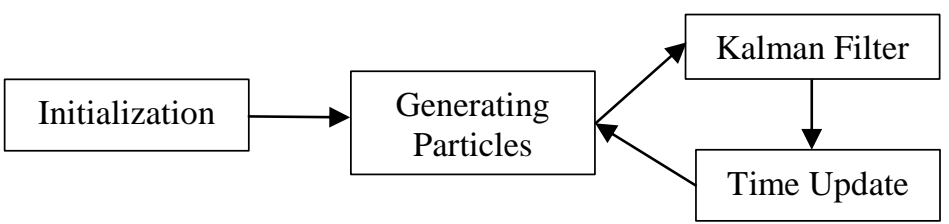

Source: authors.

In our application we performed 20 runs of the NPF with 30,000 particles each ${ }^{7}$ for a second order approximation of the nonlinear DSGE model.

\subsection{Initial values}

Before applying the NPF algorithm we estimated the model with time-invariant parameters to obtain estimates of the autoregression parameters and standard deviations of structural shocks that are considered constant even in the NPF. The posterior means of the structural parameters were also used as the initial values of the time-varying parameters $(\bar{\theta})$ in the NPF estimation. The standard deviations of time-varying parameter innovations $\left(\sigma_{v}^{\theta}\right)$ were set proportional to the posterior means ${ }^{8}$ of the model

\footnotetext{
${ }^{7}$ The particle simulation is set up in this way as a compromise between accuracy and the time demands of the calculation. By experimenting with the particle filter algorithm settings, we found that the results do not change significantly when the number of runs or the number of particles is increased.

${ }^{8}$ This choice is motivated by the large differences in the posterior standard deviations of the estimated time-invariant parameters (relative to the posterior means). Posterior standard deviations would be the natural alternative, however they capture uncertainty associated with the
} 
with time-invariant parameters (10 percent). Constant model parameters were estimated using a Random Walk Metropolis-Hastings algorithm as implemented in Dynare toolbox for Matlab; see Adjemian et al. (2011). Two parallel chains of 500,000 draws each were generated during the estimation. The first 50 percent of draws were discarded as a burn-in sample. The scale parameter was set to achieve an acceptance rate of around 30 percent.

\section{Data}

Quarterly time series of eight observables were used for the purposes of the estimation. These ESA 2010 consistent time series cover the period between the first quarter of 1999 and the third quarter of 2014 and contain 63 observations. Graphs of the observed time series are included in the appendix.

Seasonally adjusted time series of the real gross domestic product (GDP), the harmonised consumer price index (CPI), the 3-month policy interest rate (interbank offered rate) and real investment are used for the domestic economy. In the case of the Czech and Slovak economies, the foreign sector is represented by the 17 Euro area countries, while in the case of the euro area economy itself, the foreign sector is represented by the U.S. economy. The foreign sector is captured by the seasonally adjusted time series of real GDP, CPI and 3-month policy interest rate. Time series of CZK/EUR, SKK/EUR ${ }^{9}$ and EUR/USD real exchange rates are also used for the purposes of estimation. The time series were obtained from the databases of Eurostat, the Czech National Bank, the National Bank of Slovakia, the European Central Bank and the Federal Reserve Bank of St. Louis.

The original time series were transformed prior to estimation so as to express the logarithmic deviations from their respective steady states. The logarithmic deviations of the observables from their trends were calculated using a Hodrick-Prescott (HP) filter. ${ }^{10}$ In order to mitigate the HP-filter's end-of-sample bias, the level data were extended by a VAR forecast ${ }^{11}$ before the logarithmic deviations were calculated.

posterior estimate that need not have any relation to the stability of the posterior estimate in time. The parameter in question could be time-invariant and yet hard to estimate, which would yield a high posterior standard deviation. Therefore, we decided to calibrate the standard deviations of the time-varying parameters in a uniform way and let the filtration decide which parameters are time-varying.

${ }^{9}$ The values of the real exchange rate of the Slovak economy after its accession to the euro area were obtained in accordance with the model definition of the real exchange rate, i.e. by considering the development of the inflation differential.

${ }^{10}$ The HP filter parameter $\lambda$ was set to 1600 , a value commonly used for quarterly data.

${ }^{11}$ A VAR(3) model was considered for the foreign economy, while a VAR(1) model with three exogenous foreign variables was considered for the domestic economy. The forecast for the next eight quarters was calculated. Due to a structural break (adoption of the euro currency) in the Slovak economy, the time series of nominal interest rate and real exchange rate could not be included in the domestic VAR(1) model for Slovakia. 


\section{Calibration}

We decided to calibrate several deep structural parameters because they are difficult to estimate. These parameters were assigned values commonly reported in the literature. The value of discount factor $\beta$ of 0.995 implies a real interest rate of approximately 2 percent per annum. Capital share in production $\alpha$ corresponds to the national income share of capital of 0.35 . Values of around one third are commonly used in the literature. The capital depreciation rate $\delta$ of 2.5 percent per quarter is also quite standard. Households' share of labour supply $\Omega$ is calibrated according to Shaari (2008) to 99 percent, which leaves the remaining 1 percent of labour supply to be provided by the entrepreneurs. The calibration of parameter $\mu$ to 1.2 also follows Shaari (2008).

\section{Empirical results}

In this section we first look into the structural differences between the Czech and Slovak economies and the economy of the euro area as captured by time-invariant posterior estimates of the model parameters. We then make a few remarks about the development of selected unobserved endogenous variables and finally we make comparison of the time-varying parameter estimates and their interpretation in terms of the representative economic agents' behaviour.

\subsection{Posterior estimates}

The prior densities of the structural parameters are presented in Table 1. These are the same for all three economies in order to identify the structural differences in the data. A comparison of the posterior estimates of all three economies is presented in Table 2. The prior and posterior densities of the remaining model parameters are included in the appendix. Graphs of prior and posterior densities together with Brooks and Gelman (1998) convergence diagnostics (as implemented in Dynare toolbox) are included in the technical appendix.

The posterior estimates for the Slovak economy are comparable to the values obtained by Senaj et al. (2010), who estimated a two-country DSGE model for Slovakia and the euro area. Overall, the results confirm the widely recognized similarity between the Czech and Slovak economies. While most of the posterior estimates differ by less than one standard deviation, there are a few exceptions. The elasticity of the foreign bond risk-premium with respect to external position $\psi^{B}$ is estimated to be more than twice as large in Slovakia as in the Czech Republic, and three times as large as in the euro area. This result may reflect foreign creditors' higher sensitivity to developments in the relatively small and volatile Slovak economy. However, even taking this into account, the degree of uncertainty related to the estimate of this parameter for the Slovak economy is rather high. The elasticity of substitution between domestic and foreign goods $\eta$ is estimated to be slightly higher in Slovakia, which implies consumers are more sensitive to the price differential between domestic and foreign goods than in the Czech or euro area economies. 
Table 1 Prior densities (structural parameters)

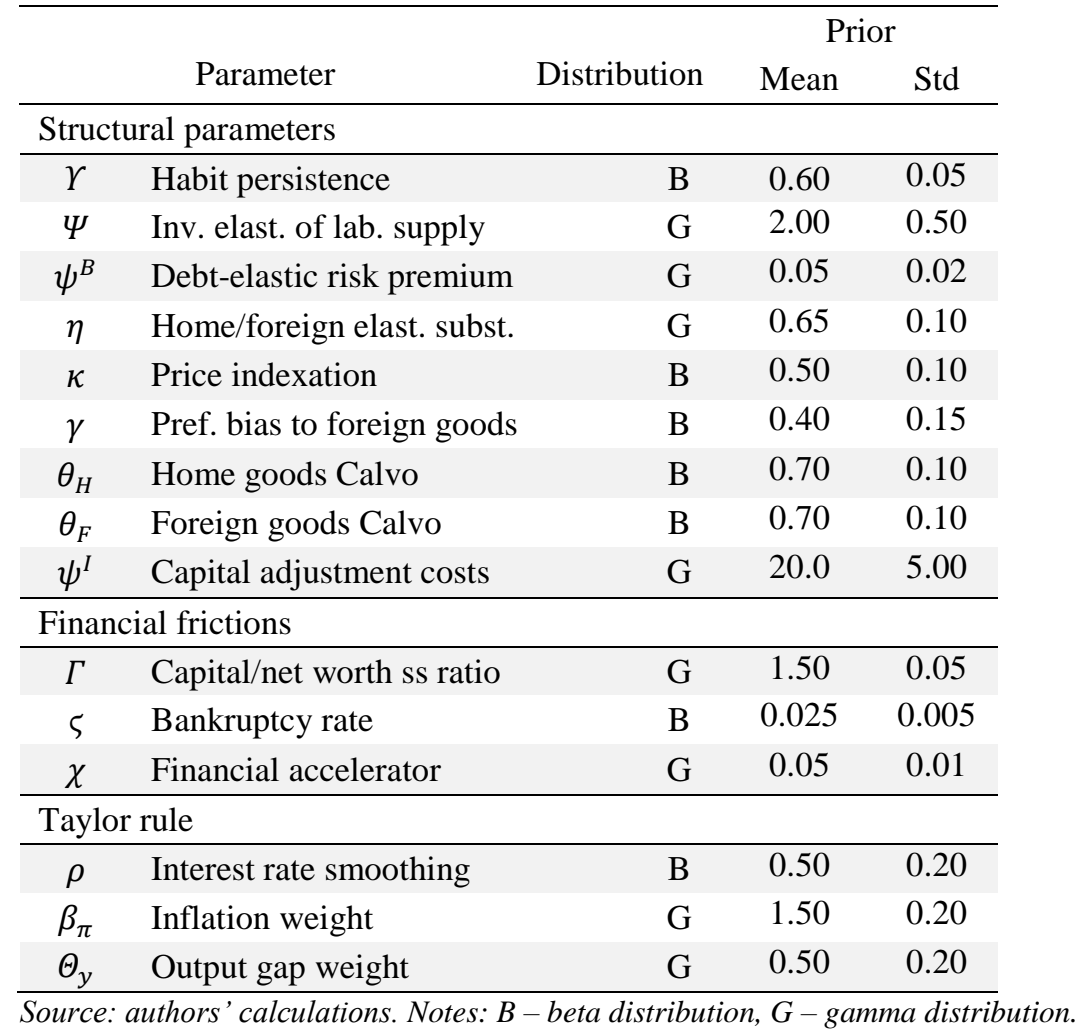

The Calvo parameters for retail firms are estimated to be lower in the Slovak economy than in the Czech economy, which may be explained by the adoption of the euro currency and the transition period and also by the fact that in the currency union firms need to update their prices more often than they would in an economy with an independent national currency, in order to remain competitive.

There are also interesting differences in the estimates of the Taylor rule parameters. While the interest rate smoothing parameter $\rho$ is estimated to be higher in the Czech economy, the weight of the output gap $\Theta_{y}$ in the Czech economy is estimated to be nearly half that in Slovakia. This suggests that the Czech National Bank is more focused on its primary goal of attaining price stability than the National Bank of Slovakia, which appears to have focused rather on the output gap.

Although the difference is smaller than one standard deviation, the inverse elasticity of labour supply $\Psi$ is estimated to be somewhat higher in the Slovak economy, which correlates to a higher natural rate of unemployment and a less flexible labour market. The estimate of the preference bias to foreign goods $\gamma$ is also slightly higher for Slovakia, which corresponds to higher openness in this small export-oriented economy. 
Table 2 Comparison of posterior means (structural parameters)

\begin{tabular}{|c|c|c|c|c|c|c|c|}
\hline \multirow{2}{*}{\multicolumn{2}{|c|}{$\begin{array}{l}\text { Parameter } \\
\text { Structural parameters }\end{array}$}} & \multicolumn{2}{|l|}{$\mathrm{CZ}$} & \multicolumn{2}{|c|}{ SK } & \multicolumn{2}{|c|}{ EA } \\
\hline & & & & & & & \\
\hline \multirow[t]{2}{*}{$r$} & Habit persistence & 0.59 & [1] & 0.58 & [0.97] & 0.65 & {$[1.1]$} \\
\hline & & $(0.053)$ & [1] & $(0.055)$ & [1.04] & $(0.071)$ & [1.33] \\
\hline \multirow[t]{2}{*}{$\Psi$} & Inv. elast. of lab. supply & 1.26 & [1] & 1.40 & [1.11] & 1.23 & [0.97] \\
\hline & & $(0.31)$ & [1] & $(0.32)$ & [1.05] & $(0.3)$ & [0.99] \\
\hline \multirow[t]{2}{*}{$\psi^{B}$} & Debt-elastic risk premium & 0.023 & [1] & 0.052 & [2.29] & 0.016 & {$[0.7]$} \\
\hline & & $(0.007)$ & [1] & $(0.015)$ & [2.25] & $(0.005)$ & [0.73] \\
\hline \multirow[t]{2}{*}{$\eta$} & Home/foreign elast. subst. & 0.61 & [1] & 0.74 & [1.21] & 0.46 & [0.75] \\
\hline & & $(0.086)$ & [1] & $(0.076)$ & [0.89] & $(0.015)$ & [0.17] \\
\hline \multirow[t]{2}{*}{$\kappa$} & Price indexation & 0.28 & [1] & 0.23 & [0.82] & 0.20 & [0.72] \\
\hline & & $(0.074)$ & [1] & $(0.062)$ & [0.84] & $(0.057)$ & [0.77] \\
\hline \multirow[t]{2}{*}{$\gamma$} & Pref. bias to foreign goods & 0.29 & [1] & 0.35 & [1.22] & 0.21 & [0.72] \\
\hline & & $(0.067)$ & [1] & $(0.052)$ & [0.77] & $(0.031)$ & [0.46] \\
\hline \multirow[t]{2}{*}{$\theta_{H}$} & Home goods Calvo & 0.81 & [1] & 0.75 & [0.92] & 0.82 & [1.02] \\
\hline & & $(0.024)$ & [1] & $(0.031)$ & [1.31] & $(0.031)$ & [1.28] \\
\hline \multirow[t]{2}{*}{$\theta_{F}$} & Foreign goods Calvo & 0.79 & [1] & 0.69 & [0.87] & 0.82 & [1.04] \\
\hline & & $(0.031)$ & [1] & $(0.038)$ & [1.24] & $(0.028)$ & {$[0.9]$} \\
\hline \multirow[t]{2}{*}{$\psi^{I}$} & Capital adjustment costs & 28.71 & [1] & 29.34 & [1.02] & 27.50 & [0.96] \\
\hline & & $(4.86)$ & [1] & $(5.25)$ & [1.08] & $(4.72)$ & [0.97] \\
\hline \multicolumn{8}{|c|}{ Financial frictions } \\
\hline \multirow[t]{2}{*}{$\Gamma$} & Capital/net worth ss ratio & 1.47 & [1] & 1.47 & [1] & 1.48 & [1.01] \\
\hline & & $(0.047)$ & [1] & $(0.047)$ & [1.01] & $(0.048)$ & [1.02] \\
\hline \multirow[t]{2}{*}{5} & Bankruptcy rate & 0.031 & [1] & 0.029 & [0.93] & 0.027 & [0.86] \\
\hline & & $(0.006)$ & [1] & $(0.005)$ & [0.93] & $(0.005)$ & [0.89] \\
\hline \multirow[t]{2}{*}{$\chi$} & Financial accelerator & 0.038 & [1] & 0.043 & [1.13] & 0.041 & [1.07] \\
\hline & & $(0.007)$ & [1] & $(0.008)$ & [1.14] & $(0.008)$ & [1.08] \\
\hline \multicolumn{8}{|c|}{ Taylor rule } \\
\hline \multirow[t]{2}{*}{$\rho$} & Interest rate smoothing & 0.86 & [1] & 0.70 & [0.81] & 0.71 & [0.82] \\
\hline & & $(0.022)$ & [1] & $(0.045)$ & [2.11] & $(0.047)$ & [2.18] \\
\hline \multirow[t]{2}{*}{$\beta_{\pi}$} & Inflation weight & 1.92 & [1] & 1.82 & [0.95] & 1.67 & [0.87] \\
\hline & & $(0.22)$ & [1] & $(0.2)$ & [0.88] & $(0.16)$ & [0.74] \\
\hline \multirow[t]{2}{*}{$\Theta_{y}$} & Output gap weight & 0.11 & [1] & 0.20 & [1.81] & 0.17 & [1.56] \\
\hline & & $(0.04)$ & [1] & $(0.06)$ & [1.48] & $(0.06)$ & [1.67] \\
\hline
\end{tabular}

Source: authors' calculations. Notes: standard deviations in parentheses, relative to $C Z$ in brackets. 
The posterior estimates for the euro area economy show stronger habits of consumption $r$. The elasticity of substitution between home and foreign goods $\eta$ is estimated to be lower in the euro area than in the Czech or Slovak economies, implying lower consumer sensitivity to price differentials. This result is complemented by a lower estimate of preference bias to the foreign goods $\gamma$, resulting from the economy's lower openness. The degree of price indexation $\kappa$ is estimated to be lower in the euro area than in the Czech economy, related to the more stable development of the inflation rate. The Taylor rule parameters for the euro area are estimated to be similar to the Slovak economy and suggest that even though price stability is clearly the primary goal, the output gap probably also plays a key role. The similarity between the Taylor rule parameters for the European Central Bank and the National Bank of Slovakia is to be expected, due to the convergence of these economies' monetary policy after Slovakia entered the ERM II exchange rate mechanism.

The financial friction parameters are estimated to be very similar across the three economies. The posterior estimates of the capital/net worth steady-state ratio $\Gamma$ roughly correspond to the debt-equity ratio of non-financial corporations; see European Central Bank (2012). The generally more stable environment of the euro area is reflected in the somewhat lower posterior estimate of the steady-state bankruptcy rate $\zeta$.

It is also worth mentioning that the estimates for most of the structural parameters for the Czech economy are closer to the estimates for the euro area than those of Slovakia, even though it is Slovakia that is a member of the euro area. This suggests that the Slovak economy is not an average economy within the euro area.

\subsection{Filtered variables}

The development of the unobserved financial market variables in the Czech, Slovak and euro area economies is depicted in Figure 6. These graphs aptly illustrate the effects of financial frictions during the Great Recession.

In the favourable period of economic boom between 2006 and 2008, the entrepreneurial net worth of firms increased, which led to lower perceived loan risks and consequently to a lower external finance premium (interest rate spread). This in turn increased the availability of debt financing and led to considerable growth in aggregate capital stock. During the financial crisis of 2008, entrepreneurial net worth decreased, first due to exogenous factors (increased systemic risk and uncertainty) and later due to the worsening economic conditions and realized losses. The external finance premium increased sharply and the consequent contraction in private investment resulted in a decline in capital stock. 
Figure 6 Comparison of selected filtered variables
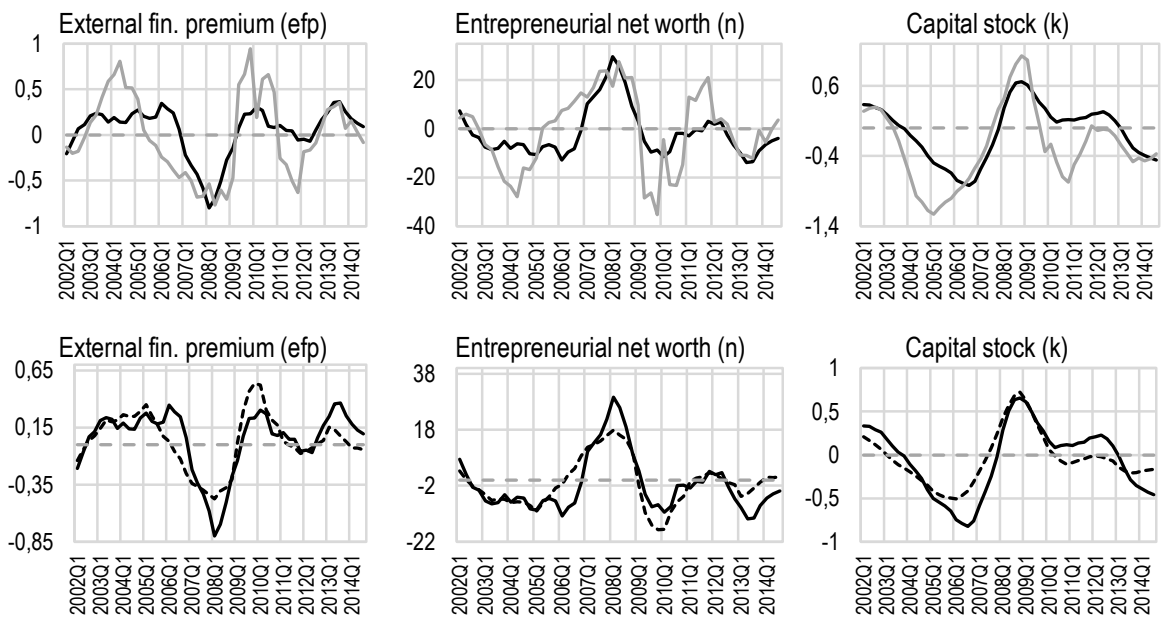

Source: authors' calculations. Notes: percentage deviations from steady state, CZ -black solid line, $S K$ - grey solid line, EA - black dashed line.

While the pre-crisis increase in entrepreneurial net worth was comparable in all three economies, the downturn after 2008 was estimated to be significantly larger in Slovakia than in the Czech economy or the euro area. This development may be related to the Czech koruna's real exchange rate depreciation in 2009, which somewhat moderated the impact of the crisis on domestic producers. According to the model, the short-term disadvantage of the fixed exchange rate in the Slovak economy was compensated for later on when the benefits of monetary union materialized. After 2010, rapid accumulation of entrepreneurial net worth was restored in Slovakia while there was a period of stagnation in the Czech economy. In this period the growth of net worth in Slovakia clearly surpassed even the euro area. The subsequent decline of entrepreneurial net worth in 2012 and 2013 can be attributed to the protracted course of the European sovereign debt crisis and the eurozone crisis. Even though the Czech economy was not hit by these events directly, growth in net worth was only restored there only after the Czech National Bank's exchange rate interventions in the final quarter of 2013.

\subsection{Filtered shock innovations}

Figure A.3 depicts the filtered shock innovations, and is to be found in the appendix A. These illustrate the turbulent period of the Great Recession similarly in all three economies. A strong negative shock came from the external environment via negative innovations in foreign output; consequently foreign demand for domestic exports dropped in the last quarter of 2008 and the first quarter of 2009. There were also noticeable disinflationary pressures from abroad in the last quarter of 2008. In the domestic economy a substantial positive innovation closed the law of one price gap as importers lowered their profit margins during the crisis. Negative innovations in entrepreneurial net worth increased the number of bankruptcies during 2008-2009, which exacerbated the recession. In Slovakia, the situation was apparently even more 
dramatic due to disturbances related to the euro conversion. The negative innovations of monetary policy shock suggest that the National Bank of Slovakia's independent monetary policy was relatively loose in the period of economic boom in 2007-2008, which may be explained by their participation in the ERM II mechanism, as the central bank struggled to maintain the exchange rate within the fluctuation band. However, the large positive innovations of the UIP shock in 2006Q4 and 2008Q2 led to appreciation pressures that had to be resolved by adjusting the central parity. The large negative UIP shock innovation in 2008Q4 suggests that the Slovak koruna would probably have depreciated during the Great Recession had it not been replaced by the euro in 2009 . The development of the net worth shock innovations also shows that the Slovak economy went through a very difficult period from the point of view of entrepreneurs between 2009 and 2012.

\subsection{Filtered time-varying parameters}

Figure 7 reports the filtered trajectories of selected time-varying parameters in the Czech and Slovak economies. Only parameters with more pronounced deviations from their initial values were selected (deviations larger than \pm 1 percent). In this section, we try to interpret the estimated changes in these structural parameters in terms of the modelled representative agents' behaviour and in terms of the real economies. However, variation in these the time-varying parameters may also reflect model misspecification. $^{12}$

The development of the financial accelerator parameter $\chi$ (the elasticity of the external finance premium with respect to the leverage ratio) in the Czech economy suggests that the commercial banks had a somewhat subdued reaction to the deteriorating leverage ratio in 2008. Commercial interest rates were not raised particularly sharply, perhaps due to initial optimism about the length and spread of the financial crisis. However, after the first quarter of 2009, the impact of the financial crisis on the real economy was becoming evident and the sensitivity of the external finance premium began to rise again. In Slovakia this decline of sensitivity was less considerable and the return to initial values was much quicker. However, a second decline in the financial accelerator comparable in size to the decline in the Czech economy can be observed during 2009 and early 2010, when the net worth of Slovak entrepreneurs deteriorated significantly.

The filtered trajectory of the steady state leverage ratio parameter $\Gamma$ shows that firms' dependency on external financing decreased during the period of economic boom in 2007-2008 in both the Czech and Slovak economies. However, this development was reversed after the last quarter of 2008 due to worsening macroeconomic conditions. The economic crisis' more severe impact on the Slovak economy than on the Czech economy is reflected in a larger increase in the share of external funds held by domestic firms in the Slovak economy.

\footnotetext{
${ }^{12}$ This may be particularly relevant as the model used for our analysis is rather simple. The results presented in this section could alternatively be used to assess which parts of the model are substantially misspecified.
} 
Figure 7 Comparison of selected time-varying parameters (CZxSK)

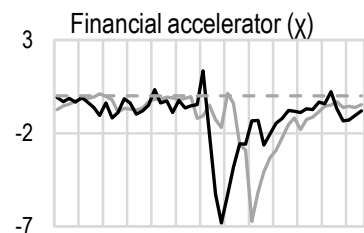

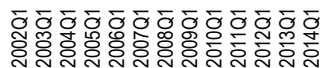

Dom./for. elast. of subst. (n)

4

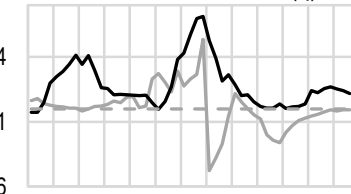

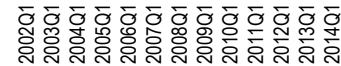

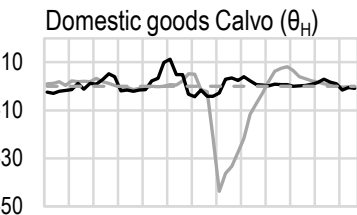

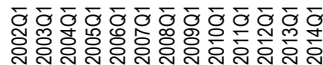

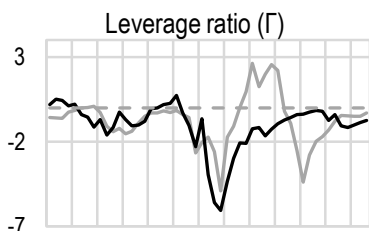

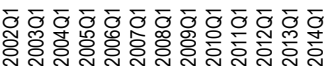
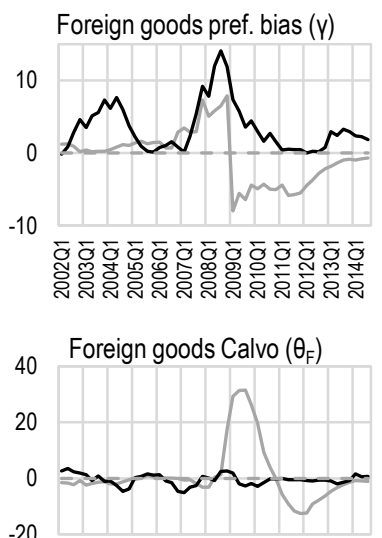

$-20$

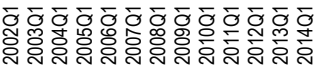

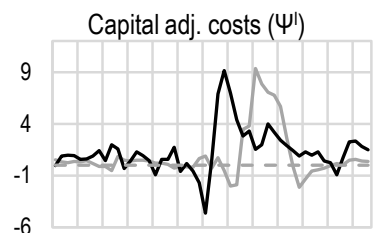

$\bar{\delta} \bar{\delta} \bar{\delta} \bar{\delta} \bar{\delta} \bar{g} \bar{\delta} \bar{\delta} \overline{0} \bar{d} \bar{\delta} \bar{\sigma}$

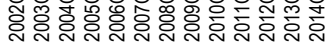
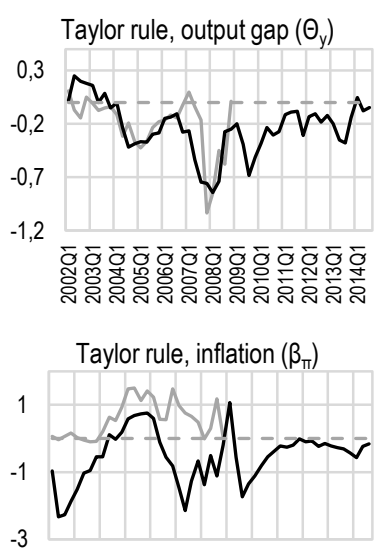

$-3$

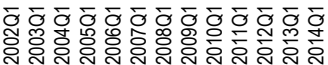

Source: authors' calculations. Notes: percentage deviations from initial values, CZ - black solid line, SK - grey solid line.

The increasing capital adjustment costs parameter $\psi^{I}$ in the Czech economy during 2008 could be explained by the increasing difficulty of finding viable investment opportunities in an arguably overheated economy, and would indicate that an increasing share of investment was being made inefficiently. In the Slovak economy similar developments occurred in the second half of 2009, when the European debt crisis was looming and the inflow of foreign direct investment stalling.

Overall, the filtered trajectories of the financial friction parameters suggest that the situation in the financial sector of the Czech economy was changing as early as 2008, while in Slovakia prospects were still quite positive in light of the anticipated adoption of the euro, and the situation became turbulent only after the actual impact of the economic crisis in 2009 and the European debt crisis in 2010.

The elasticity between domestic and foreign goods $\eta$ and the foreign goods preference bias $\gamma$ (the share of foreign goods in consumption) tell a similar story. As the volume of international trade increased in the pre-crisis period, the share of imported goods also increased, as did the sensitivity of domestic economic agents to the price differential between domestic and foreign goods. Over the course of the crisis the situation reversed. The current development of these parameters suggests that the situation in the 
Slovak economy is roughly stable while in the Czech economy the increase of these parameters could be related to a recovery of consumer confidence.

The filtered trajectories of the Taylor rule parameters are more or less stable. Given the strict nature of the inflation targeting regime in the Czech economy, the stability of the weight of the inflation gap $\beta_{\pi}$ should be no surprise. Also, the monetary policy of Slovakia, as a eurozone candidate, would be expected to follow the development of inflation closely (in order to meet the requirements for euro adoption), while the output gap would not necessarily be a priority. The mostly negative deviations of the output gap weight $\Theta_{y}$ from its initial value would indeed suggest that the Czech and Slovak central banks did not place much importance on the output gap in their decision making.

Finally, the Calvo parameters, which capture the price stickiness of domestic and foreign goods retailers, show distinct deviations from their initial values. The most significant deviation in the time-varying parameters is identified in the Slovak economy during the transition period after the euro changeover. The price rigidity of domestic retail firms $\theta_{H}$ is estimated to have almost halved its initial value. At the same time the price rigidity of importing retail firms $\theta_{F}$ increased significantly. Obviously, the currency changeover represented an opportunity for domestic firms to round up and adjust the prices of their products, and at the same time made it more important to monitor the pricing strategy of competitors. Therefore, in the transition period before new prices are settled, lower price rigidity should be expected. The increased price rigidity of importers can be explained by the favourable setting of the conversion rate of the Slovak koruna and disinflationary tendencies in the foreign economy, which enabled importers to remain competitive with their prices relatively unchanged.

The development of selected time-varying parameters in the Czech economy and the economy of the euro area is depicted in Figure 8. The estimated deviations of the financial sector parameters in the euro area are mostly in the same direction but with much larger amplitudes than in the Czech economy. This corresponds to the more immediate impact of the financial crisis on western European countries compared to the relatively sheltered economies of Central Europe. The destabilizing impact of the European debt crisis in the euro area is noticeable in early 2010. Since mid-2010 the situation on the financial market in the euro area seems to have been gradually stabilizing.

During the Great Recession the elasticity of substitution between foreign and domestic goods $\eta$ and the foreign goods preference bias $\gamma$ declined, together with the volume of international trade. After a short-lived correction, these two parameters began to decline again in 2010 due to the sovereign debt crisis in the euro area. Recent estimates of these parameters indicate stabilization in this area as well. 
Figure 8 Comparison of selected time-varying parameters (CZxEA)

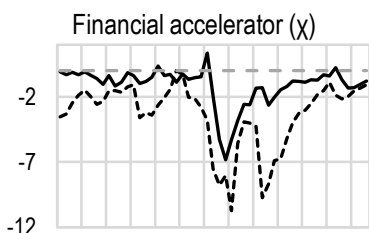

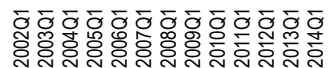

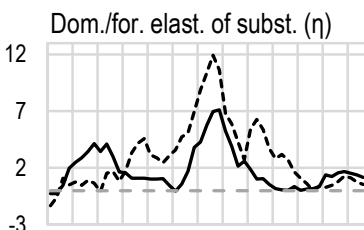

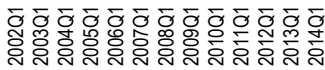

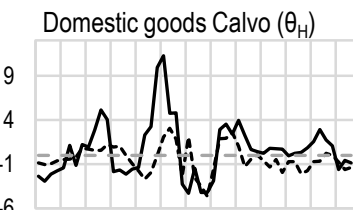

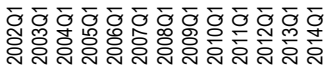

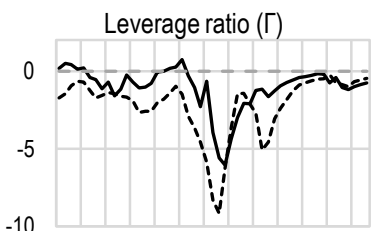

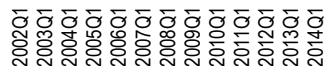

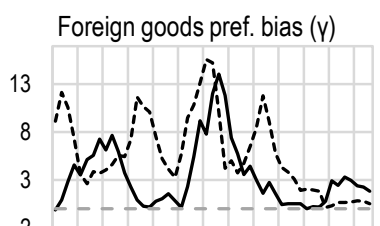

$-2$
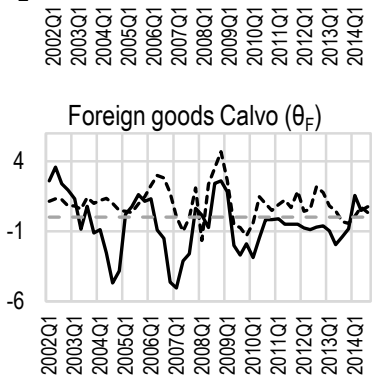

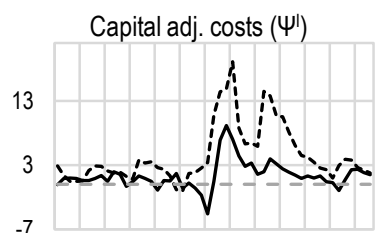

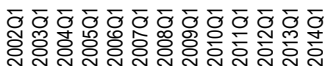

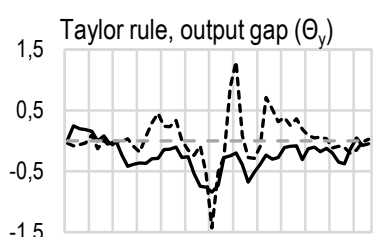

$-1,5$

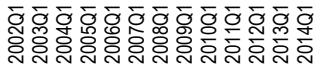

Taylor rule, inflation $\left(\beta_{\pi}\right)$

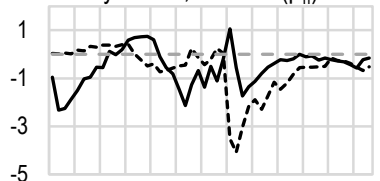

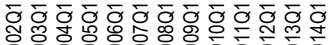

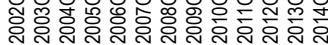

Source: authors' calculations. Notes: percentage deviations from initial values, $C Z$ - black solid line, EA-black dashed line.

The filtered trajectories of the Calvo parameters in the Czech economy and the euro area show declining rigidity of the prices of domestic goods $\theta_{H}$ during 2007 and 2008. In this period of economic boom, demand was strong and wage growth likewise. On the other hand, the rigidity of the prices of imported goods $\theta_{F}$ is estimated to have increased in the same period, probably due to the appreciation of the real exchange rate easing supply-side pressures. During 2009 this situation reversed, as foreign demand faltered, domestic supply-side pressures eased and the real exchange rate depreciated. After 2010, the Calvo parameters returned to the vicinity of their initial values. In the Czech economy, the domestic Calvo parameter increased due to weak demand during the 2012-2013 recession, which intensified disinflationary pressures. After the Czech National Bank's exchange rate intervention in the final quarter of 2013 put importers' prices under pressure, the Calvo parameter for importing firms increased above its initial value. As domestic demand in the Czech economy was relatively weak, the importers were willing to absorb part of the cost increase in their profit margins, thus increasing price stickiness. The rising prices of imported goods (although subdued) made room for domestic producers of substitute goods to slightly increase their prices as well, which is reflected in the decline of the domestic Calvo parameter. This development is in line with the expected impact of the exchange rate intervention as 
communicated by the Czech National Bank, and suggests that the intervention was successful in its main goal of avoiding deflation in the Czech economy.

The downward deviation of inflation weight in the Taylor rule $\beta_{\pi}$ in the euro area in 2009 hints at the ECB's relatively weak reaction to the impact of the financial crisis. This was probably caused by the ECB underestimating the effects of the U.S. subprime mortgage crisis on European countries. In the Czech economy, the effects of the financial crisis were also probably underestimated at first, since the inflation weight also declined below its initial value during 2009.

In order to assess the statistical significance of the time-varying parameter changes we took the $95 \%$ highest posterior density intervals (HPDI) from the models with timeinvariant parameters and compared them with the corresponding estimated time-varying trajectories. We consider changes in the time-varying parameters that exceed the $95 \%$ HPDI bounds to be statistically significant. In the Czech economy the Calvo parameter for increase of domestic goods $\theta_{H}$ before the crisis and the decline of the leverage ratio $\Gamma$ during the crisis are statistically significant. In the Slovak economy, the changes in both the Calvo parameters after euro adoption are highly significant, while the fluctuation of the leverage ratio during the crisis only borders on being statistically significant at the given level of significance. In the euro area economy, the increase in the elasticity of substitution between domestic and foreign goods $\eta$ and the decline in the leverage ratio during the crisis are statistically significant. The changes in both the Calvo parameters during the crisis are on the verge of statistical significance.

Figure 9 contains the filtered trajectories of the time-varying adhesion parameter $\alpha^{\theta}$ for all three economies. The value of this parameter affects the general tendency of the remaining time-varying parameters in each economy to return to their initial values.

Figure 9 Comparison of time-varying adhesion parameters

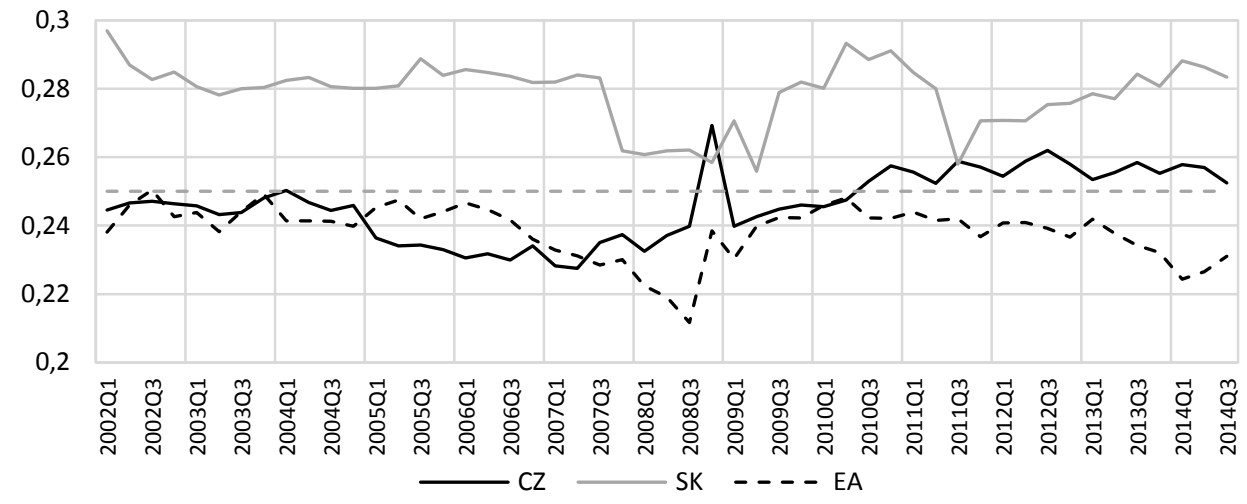

Source: authors' calculations.

We can see that the values of the adhesion parameters range from 0.21 to 0.29 . The lowest adhesion is achieved in the euro area in 2008Q3, and the highest is observed in the Slovak economy in 2002Q1. Adhesion in the Slovak economy is estimated to be 
slightly higher than in the other two economies, at close to 0.28 . There is a distinct decline in adhesion in the Slovak economy between the end of 2007 and 2009, which corresponds to the period of preparation for euro adoption, when necessary reforms were undertaken. In the Czech economy adhesion declined between 2005 and 2008, while in the euro area economy it declined between 2006 and 2008. This development corresponds to the pre-crisis period of economic growth when the economies were moving further and further away from their respective steady states. The increase in adhesion during 2008-2009 can be interpreted as a correction of these previously accumulated imbalances. Recently, adhesion has been increasing in the Slovak economy, which implies that the structure of the Slovak economy has become firmer. The situation in the euro area is exactly the opposite, implying a potential increase in instability. In the Czech economy, the adhesion parameter is currently fluctuating close to its initial value of 0.25 .

\subsection{Time-varying impulse response functions}

In order to assess the economic significance of the estimated changes in the timevarying structural parameters we calculated time-varying impulse responses to $1 \%$ innovations in exogenous shocks. We wanted to see the impact of the changing values of the model parameters on the behaviour of the model economy. In this paper we focus on the impulse responses of the real GDP in order to stay concise. Figures A.4 to A.6 in appendix A present the time-varying impulse responses of real GDP to the exogenous shocks.

The time-varying impulse responses of real output in the Czech economy show varying sensitivity to the law of one price, net worth, productivity and to some extent monetary policy shock during the crisis. We can also see that the amplitude and shape of the impulse responses varied before the crisis, especially in the case of the law of one price shock. Furthermore, we can see that the impulse responses to the net worth shock and the productivity shock during the crisis departed from the interval of their pre-crisis fluctuations, while the impulse responses to the law of one price shock and monetary policy shock shifted to the limit of the pre-crisis interval. These results show that the behaviour of the Czech economy changed quite markedly during the crisis.

The changes in the impulse responses of Slovak real GDP to the exogenous shocks are predominantly caused by the monetary policy regime switch that took place during the crisis. Nevertheless, it can be seen that the impulse responses to the law of one price shock and net worth shock were also affected by the changes in the time-varying parameters to some extent.

In the case of the euro area, similar conclusions can be drawn from the time-varying impulse responses as in the case of the Czech economy. Again, we observe extreme responses to the law of one price, net worth and productivity shocks. In case of the law of one price shock, the responses depart from the pre-crisis interval. Furthermore, we observe considerable changes in the shape of responses to the foreign interest rate and foreign output shocks, which we did not see with the Czech economy. These results suggest that the euro area economy's reactions to domestic as well as foreign shocks during the crisis changed as a result of changes in the time-varying parameters. 


\section{Conclusion}

In this paper, we have presented the results of our estimation of three DSGE models with time-varying parameters using a nonlinear particle filter. A small open economy model was estimated for the Czech economy and for the economy of the euro area, and a similar model with a deterministic regime switch was estimated for the economy of Slovakia.

The results of the estimation with time-invariant parameters confirmed the similarity of the Czech and Slovak economies and showed that in certain respects the structure of the Czech economy might be closer to that of the euro area than that of Slovakia. The timevarying estimates showed many similarities between the parameter changes in the Czech economy and the euro area during the Great Recession. The main characteristics of the development of financial sector parameters, Calvo parameters and also the parameters capturing the preferences toward foreign goods and international trade were very similar. In Slovakia, the euro adoption caused large deviations in the Calvo parameters that nearly eclipsed everything else. Since the euro adoption was anticipated by economic agents, it affected the development of the Slovak economy even before the actual currency conversion and made the development of the structural parameters in the Slovak economy both before and during the Great Recession rather specific.

The filtered trajectories of the financial frictions parameters correspond to the earlier and more immediate impact of the financial crisis on the euro area countries than on the relatively sheltered economies of the Czech Republic and Slovakia. The filtered trajectories also suggest that the situation in the financial sector of the Czech economy was changing as early as in 2008, while in Slovakia prospects were still quite positive in light of the anticipated euro adoption and the situation became turbulent only after the actual impact of the economic crisis in 2009 and the European debt crisis in 2010. During the transition period after the euro changeover, we identified large deviations in the filtered trajectories of the Calvo parameters for the Slovak economy. The currency changeover represented an opportunity for domestic firms to round up and adjust prices and at the same time made it more important to monitor their competitors' pricing strategies. Therefore lower price rigidity could be expected during the transition period, before the new prices were settled. The destabilizing impact of the European debt crisis is noticeable in the trajectories of the financial frictions parameters of the euro area and Slovakia in 2010. During 2010 and 2011 the situation on the financial markets gradually stabilized. Recent results for the time-varying parameter estimations for the Czech economy suggest that the CNB's exchange rate intervention probably helped to avert deflation in the Czech economy, since it led to a decline in domestic firms' price rigidity.

The most recent time-varying parameter estimates for all three economies are in the vicinity of their initial values; the economies seem to be stabilized. According to recent time-varying estimates of the adhesion parameter, the structure of the Slovak economy is becoming slightly firmer, while the structure of the euro area economy is becoming somewhat looser. Adhesion in the Czech economy remains relatively stable.

The trajectories of the time-varying parameters should be interpreted with caution. In this paper, we have tried to interpret the estimated changes in the structural parameters in terms of the behaviour of the modelled representative agents, and in terms of real 
economies. However, variation in the time-varying parameters might also reflect model misspecification. This means that the time-varying parameter estimates could potentially be used to identify the most problematic parts of our model.

Using the $95 \%$ highest posterior density intervals from the model with time-invariant parameters we found that the changes in the Calvo parameters and steady-state leverage ratio were statistically significant or bordering on being statistically significant in all three examined economies. The economic significance of the time-varying parameters changes was evaluated using the time-varying impulse responses of real GDP. In the cases of law of one price, net worth and productivity shocks, unprecedented impulse responses were observed in all three economies during the crisis.

Acknowledgements: The views expressed here are those of the authors and do not necessarily reflect the position of the National Bank of Slovakia. The authors would like to thank to Daniel Němec, Jaromír Tonner and Jan Brůha for their advice and helpful comments. Access to computing and storage facilities owned by parties and projects contributing to the National Grid Infrastructure MetaCentrum, provided under the programme "Projects of Large Infrastructure for Research, Development, and Innovations" (LM2010005), is greatly appreciated. The paper is part of Masaryk university research project MUNI/A/1040/2015.

Disclosure statement: No potential conflict of interest was reported by the authors.

\section{References}

ADJEMIAN, S., BASTANI, H., JUILlARD, M., KARAMÉ, F., MIHOUBI, F., PERENDIA, G., PFEIFER, J., RATTO, M. and VILLEMOT, S. (2011). Dynare: Reference Manual, Version 4, Dynare Working Papers, 1, CEPREMAP.

BERNANKE, B. S., GERTLER, M. and GILCHRIST, S. (1999). The Financial Accelerator in a Quantitative Business Cycle Framework, in Taylor, J. B. and Woodford, M. (eds.), Handbook of Macroeconomics, vol. 1, Elsevier, Amsterdam, 1341-1393.

BROOKS, S. P. and GELMAN, A. (1998). General methods for monitoring convergence of iterative simulations, Journal of computational and graphical statistics, 7(4), 434-455.

ČAPEK, J. (2012). Comparison of recursive parameter estimation and non-linear filtration, in Ramík, J. and Stavárek, D. (eds.), Mathematical Methods in Economics 2012. Karviná, Silesian University, School of Business Administration, 85-90.

CHRISTIANO, L. J., TRABANDT, M. and WALENTIN, K. (2011). Introducing Financial Frictions and Unemployment into a Small Open Economy Model, Journal of Economic Dynamics and Control, 35 (12): 1999-2041. DOI: 10.1016/j.jedc.2011.09.005

European Central Bank (2000). EU Banks' Margins and Credit Standards, December 2000. 
European Central Bank (2012). Corporate Indebtedness in the Euro Area, ECB Monthly Bulletin, 2012 (February): 87-103.

HAUG, A. J. (2005). A Tutorial on Bayesian Estimation and Tracking Techniques Applicable to Nonlinear and Non-Gaussian Processes, Mitre Technical Report, MITRE corporation, http://www.mitre.org/sites/default/files/pdf/05_0211.pdf.

JUSTINIANO, A. and PRESTON, B. (2006). Monetary Policy and Uncertainty in an Empirical Small Open Economy Model, Journal of Applied Econometrics, 25 (1): 93128. DOI: $\underline{10.1002 / j a e .1153}$

NĚMEC, D. (2013). Investigating Differences Between the Czech and Slovak Labour Market Using a Small DSGE Model with Search and Matching Frictions, The Czech Economic Review, 7 (1): 21-41.

RYŠÁNEK, J., TONNER, J., TVRZ, S. and VAŠÍČEK, O. (2012). Monetary policy implications of financial frictions in the Czech Republic, Czech Journal of Economics and Finance, 62 (5): 413-429.

SENAJ, M., VÝŠKRABKA, M. and ZEMAN, J. (2010). MUSE: Monetary Union and Slovak Economy Model, Ekonomický časopis, 60 (5): 435-459.

SHAARI, M. H. (2008). Analyzing Bank Negara Malaysia’s Behaviour in Formulating Monetary Policy: An Empirical Approach. [Doctoral thesis.] Canberra: College of Business and Economics, Australian National University.

TVRZ, S. (2014). Czech and Slovak economy during the Great Recession through the lens of a DSGE model, in Brezina, J. et al. (eds.), Economic Theory \& Economic Reality ETER 2014. Bratislava, Economic University.

TVRZ, S. and VAŠÍČEK, O. (2014). Nonlinear DSGE model of a small open economy with time-varying parameters: Czech economy in a period of recession, in Talašová, J., Stoklasa, J. and Talášek, T. (eds.), Mathematical Methods in Economics 2014. Olomouc, Palacký University, 1068-1073.

TVRZ, S. and VAŠÍČEK, O. (2015). 'Slovak economy in a period of recession: Nonlinear DSGE model with time-varying parameters', Ekonomický časopis, 63 (1): 3450 .

TVRZ, S. and VAŠÍČEK, O. (2016). The Great Recession in the Non-EMU Visegrád Countries: A Nonlinear DSGE Model with Time-Varying Parameters, Czech Journal of Economics and Finance. Volume 66, Issue 3, pages 207-235.

VAŠÍČEK, O., TONNER, J. and POLANSKÝ, J. (2011). Parameter Drifting in a DSGE Model Estimated on Czech Data, Czech Journal of Economics and Finance, 61 (5): 510-524.

ŽÚDEL, B. and MELIORIS, L. (2016). Five Years in a Balloon: Estimating the Effects of Euro Adoption in Slovakia Using the Synthetic Control Method, Economics Department Working Papers, No. 1317, OECD. 


\section{Appendix A}

Figure A.1 Source data (CZ, SK)

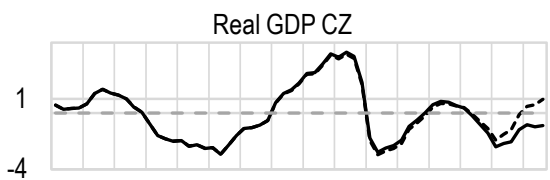

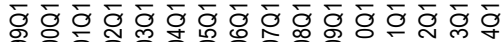

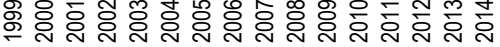

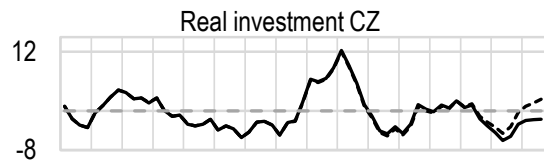

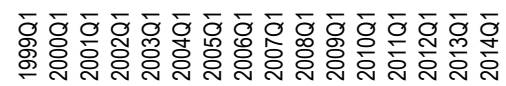

Real GDP SK

4

$-6$

$\bar{\delta} \bar{\delta} \bar{\sigma} \bar{\delta} \bar{\delta} \bar{\sigma} \bar{\delta} \bar{\delta} \bar{\delta} \bar{\delta} \bar{\delta} \bar{\sigma} \bar{\alpha} \bar{\gamma} \bar{\sigma}$

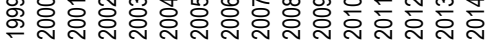

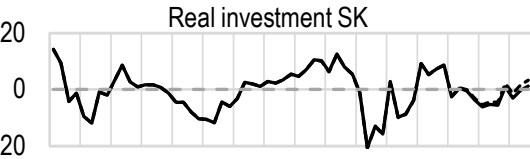

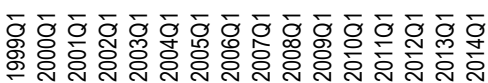

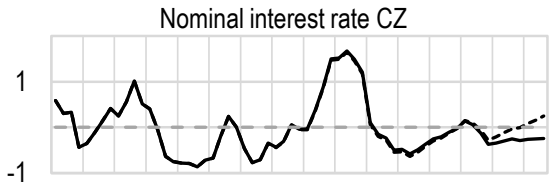

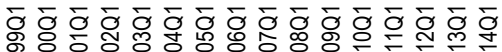

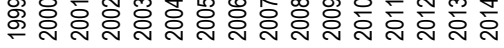

$-12$

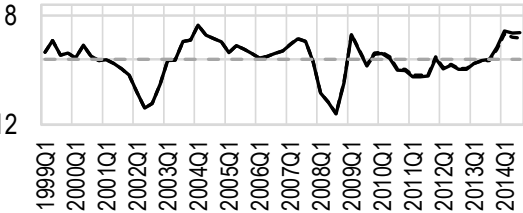

HICP inflation $\mathrm{CZ}$

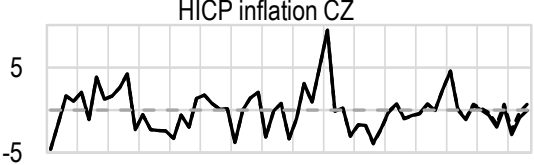

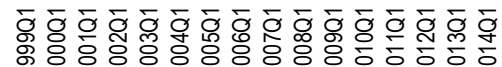

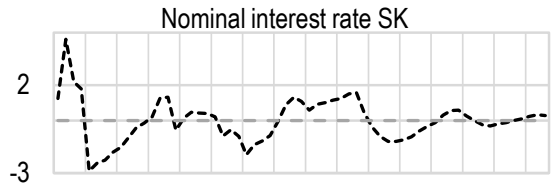

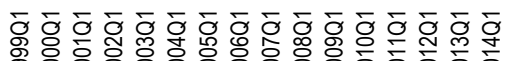

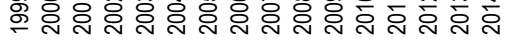

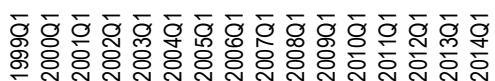

Source: authors' calculations. Notes: percentage deviations from steady state, data detrended with VAR forecast - black solid line, data detrended without VAR forecast-black dashed line. 
Figure A.2 Source data (EA, US)

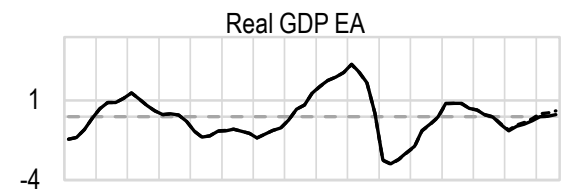

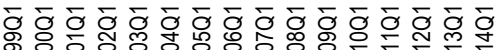

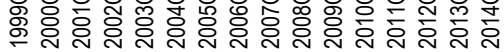
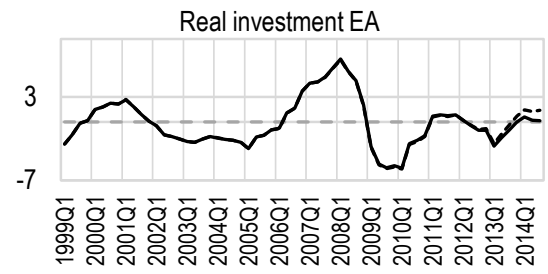

3

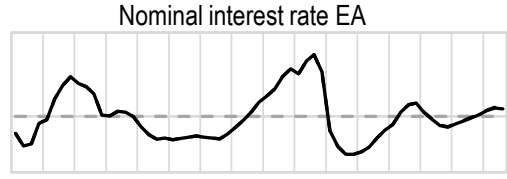

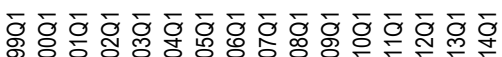

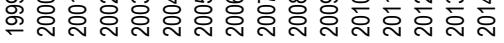

HICP inflation EA

1

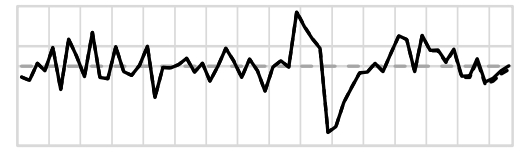

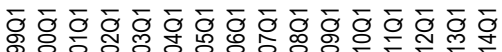

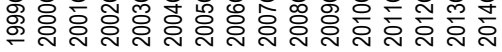

Real GDP US

2

$-3$

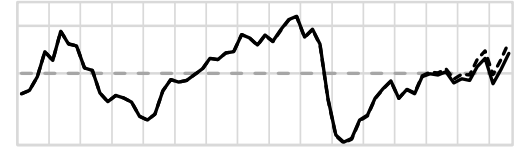

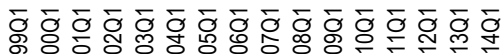

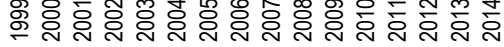

20

$-20$

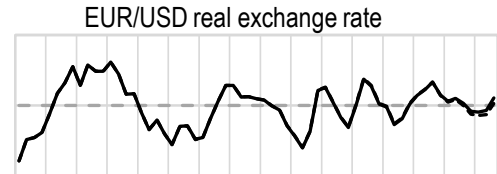

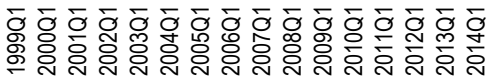

3

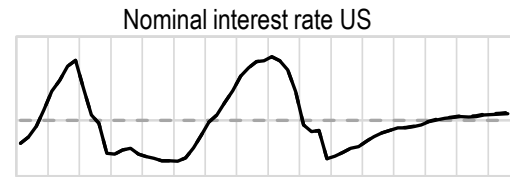

$-2$

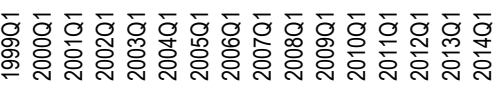

$-10$

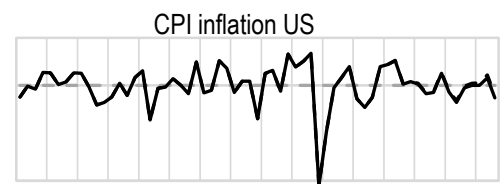

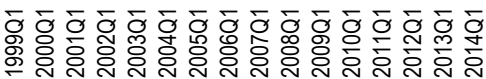

Source: authors' calculations. Notes: percentage deviations from steady state, data detrended with VAR forecast - black solid line, data detrended without VAR forecast-black dashed line. 
Figure A.3 Filtered shock innovations
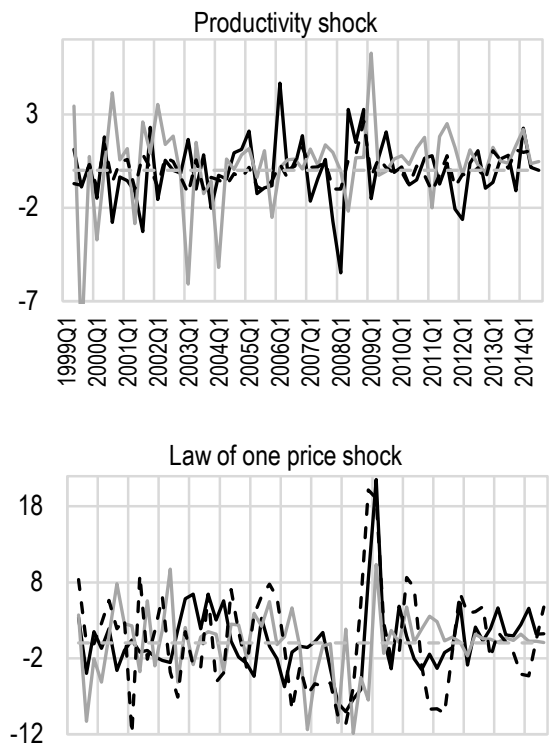

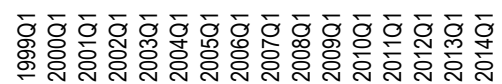
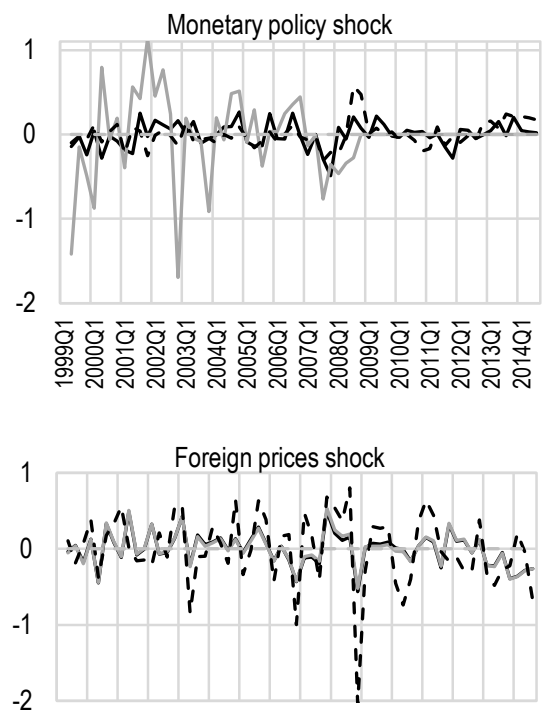

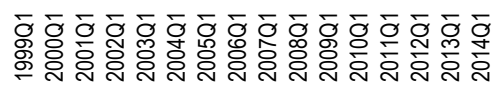
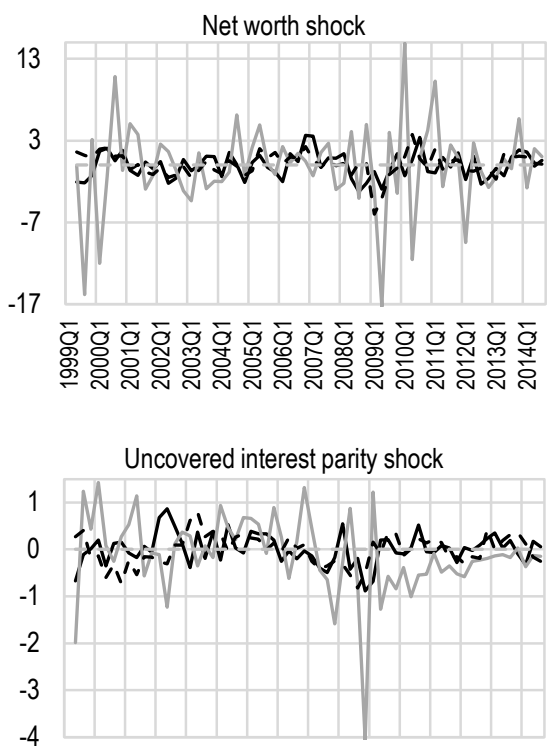

$\bar{\delta} \bar{\delta} \bar{\sigma} \bar{\sigma} \bar{\sigma} \bar{\sigma} \bar{\sigma} \bar{\sigma} \bar{\sigma} \bar{\sigma} \bar{\sigma} \bar{\sigma} \bar{\sigma} \bar{\sigma} \bar{\sigma} \bar{\sigma} \bar{\sigma}$

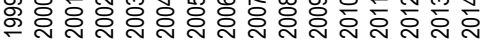

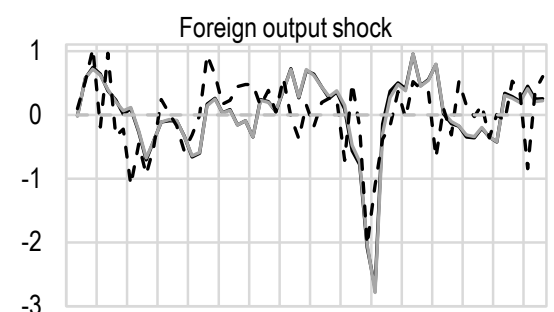

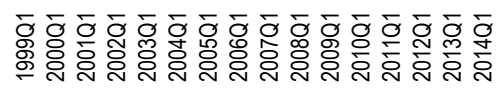

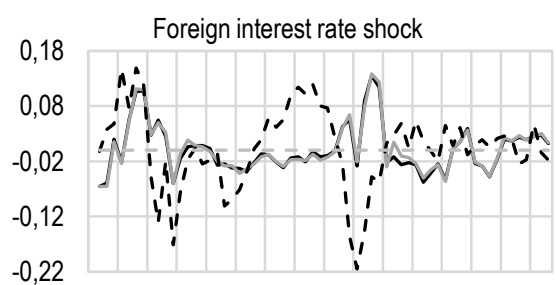

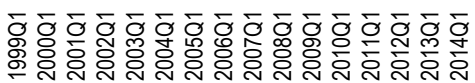

Source: authors' calculations. Notes: percentage deviations from initial values, $C Z$ - black solid line, $S K$ - grey solid line, EA - black dashed line. 
Figure A.4 Time varying impulse responses of real GDP (CZ)
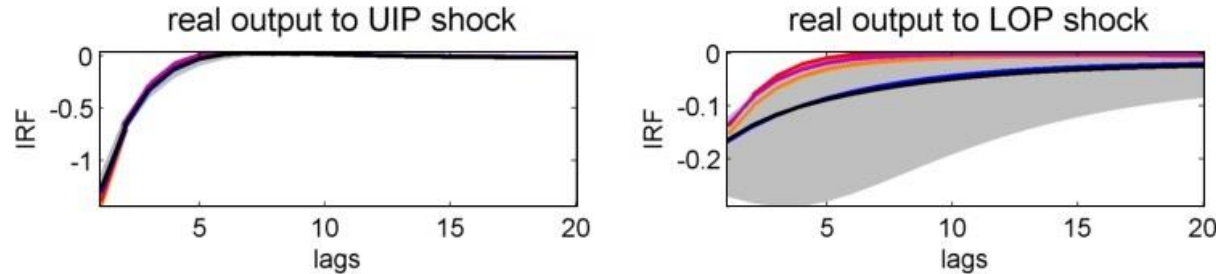

real output to foreign interest rate shock

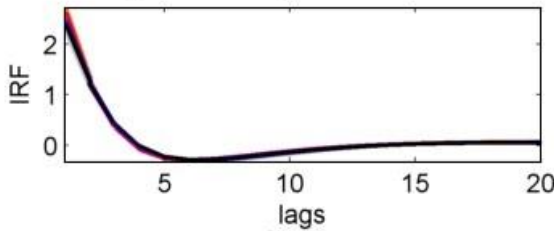

real output to foreign inflation shock

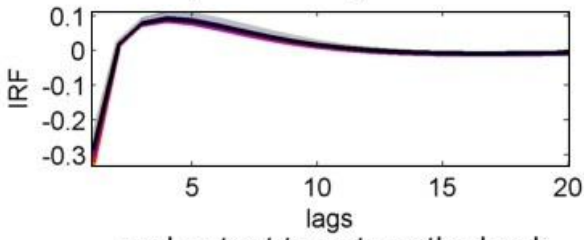

real output to foreign output shock
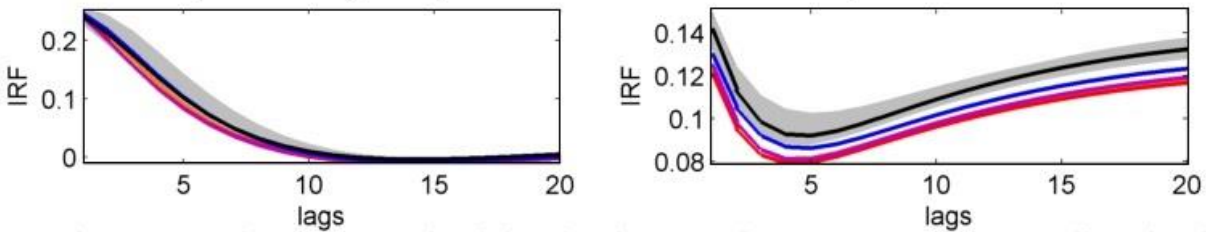

real output to domestic productivity shock real output to monetary policy shock
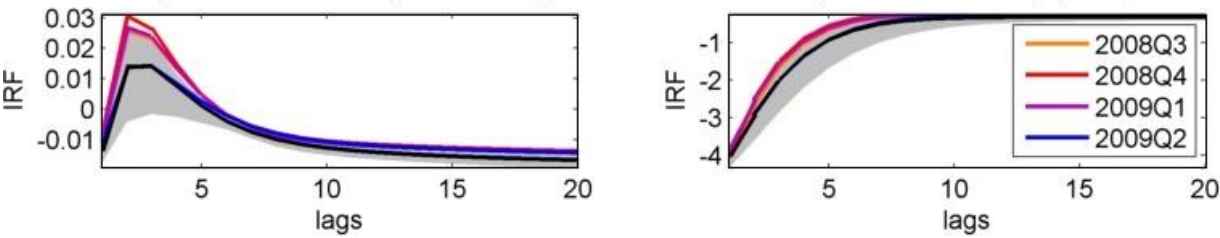

Source: authors' calculations. Notes: Impulse responses to 1\% shocks are depicted, shaded area - pre-crisis period (2003Q3-2008Q2), black line - pre-crisis mean. 
Figure A.5 Time varying impulse responses of real GDP (SK)
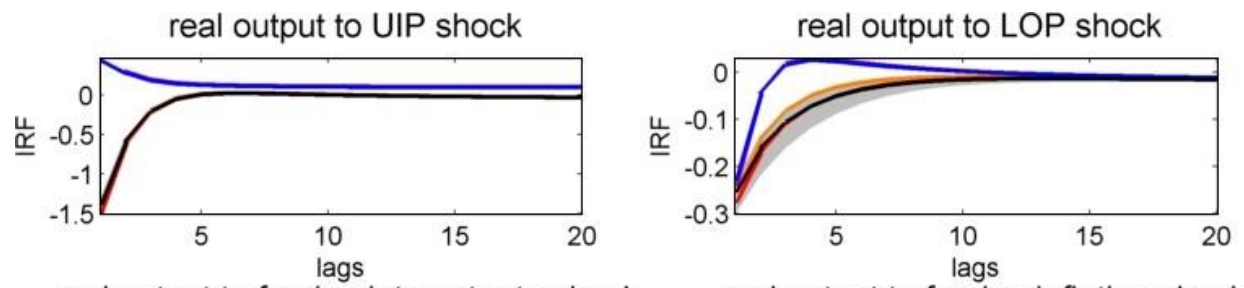

real output to foreign interest rate shock
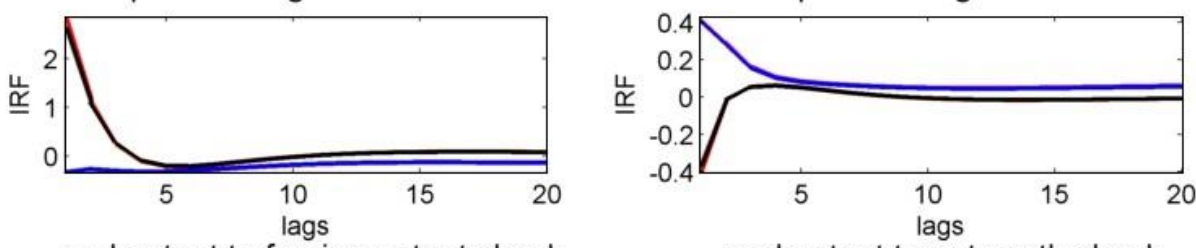

real output to foreign output shock

real output to net worth shock
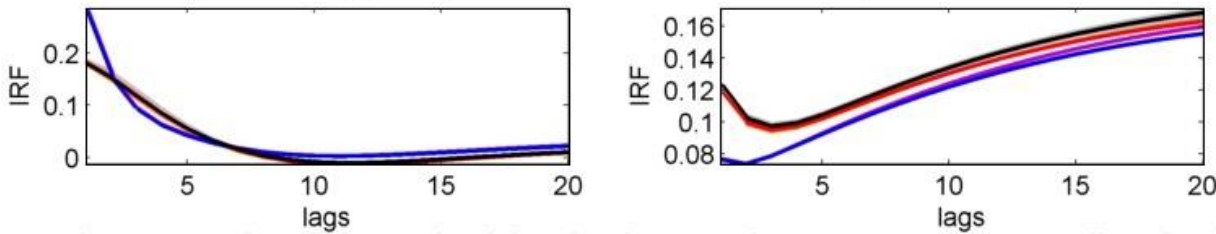

real output to domestic productivity shock
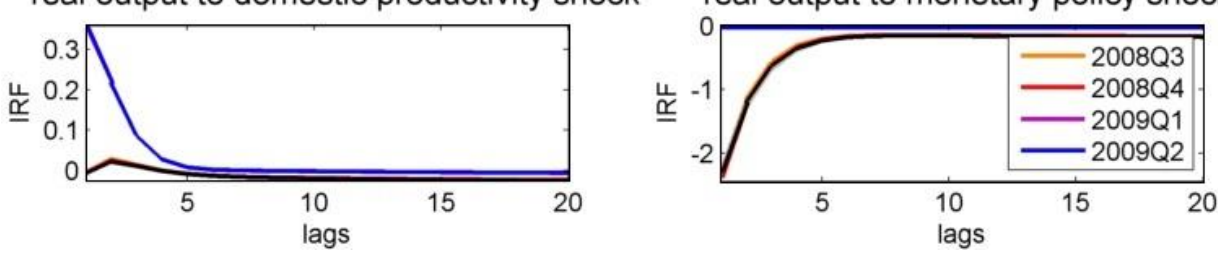

Source: authors' calculations. Notes: Impulse responses to $1 \%$ shocks are depicted, shaded area - pre-crisis period (2003Q3-2008Q2), black line - pre-crisis mean. 
Figure A.6 Time varying impulse responses of real GDP (EA)
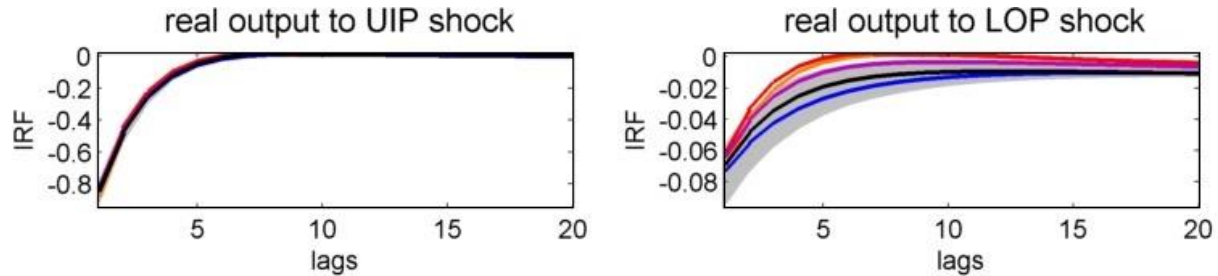

real output to foreign interest rate shock
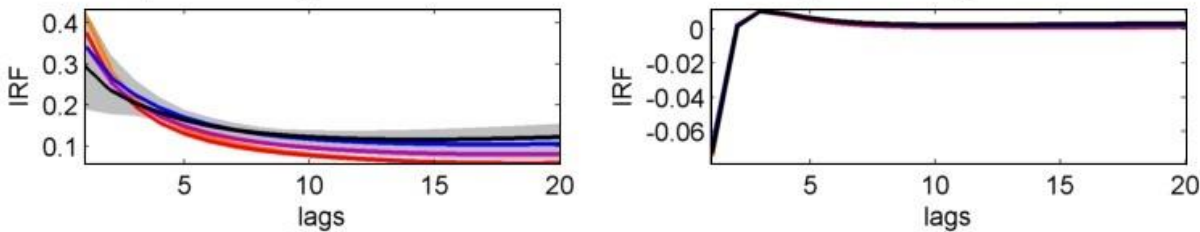

real output to foreign output shock

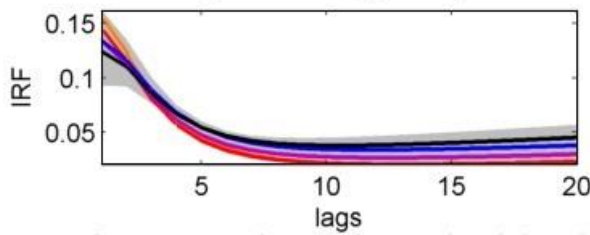

real output to net worth shock

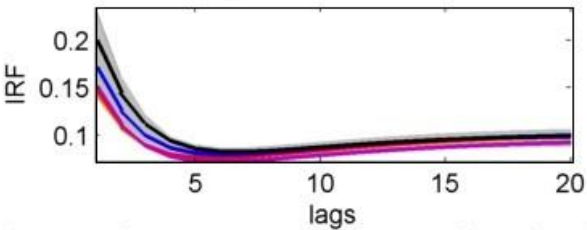

real output to domestic productivity shock
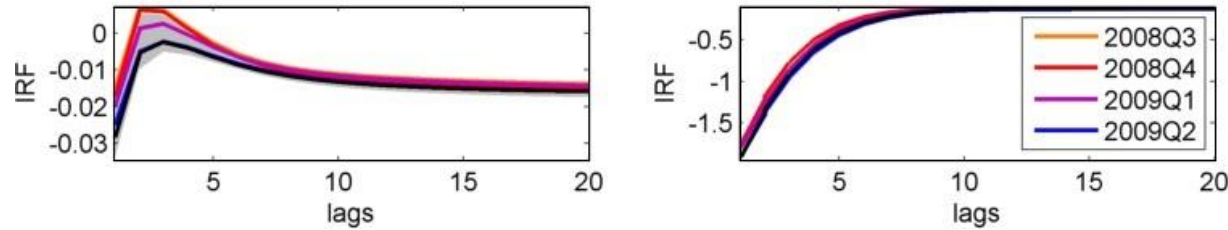

Source: authors' calculations. Notes: Impulse responses to $1 \%$ shocks are depicted, shaded area - pre-crisis period (2003Q3-2008Q2), black line - pre-crisis mean. 
Table A.1 Prior densities (exogenous processes)

\begin{tabular}{lllll}
\hline \multicolumn{1}{c}{ Parameter } & Distribution & Mean & Std \\
\hline Shock persistences & & & \\
\hline$\rho_{Y}$ & Productivity shock & $\mathrm{B}$ & 0.5 & 0.2 \\
$\rho_{U I P}$ & UIP shock & $\mathrm{B}$ & 0.5 & 0.2 \\
$\rho_{L O P}$ & LOP shock & $\mathrm{B}$ & 0.5 & 0.2 \\
$\rho_{N W}$ & Net worth shock & $\mathrm{B}$ & 0.5 & 0.2 \\
\hline Shock volatilities & & & \\
\hline$\sigma_{Y}$ & Productivity shock & $\mathrm{IG}$ & 1 & $\infty$ \\
$\sigma_{U I P}$ & UIP shock & $\mathrm{IG}$ & 1 & $\infty$ \\
$\sigma_{L O P}$ & LOP shock & $\mathrm{IG}$ & 1 & $\infty$ \\
$\sigma_{N W}$ & Net worth shock & $\mathrm{IG}$ & 1 & $\infty$ \\
$\sigma_{M P} \quad$ Monetary policy shock & $\mathrm{IG}$ & 0.1 & $\infty$ \\
$\sigma_{y^{*}}$ & Foreign output & $\mathrm{IG}$ & 0.5 & $\infty$ \\
$\sigma_{\pi^{*}}$ & Foreign CPI inflation & $\mathrm{IG}$ & 0.2 & $\infty$ \\
$\sigma_{i^{*}}$ & Foreign interest rate & $\mathrm{IG}$ & 0.1 & $\infty$ \\
\hline
\end{tabular}

Source: authors' calculations. Notes: B-beta distribution, IG-inverted gamma distribution. 
REVIEW OF ECONOMIC PERSPECTIVES

Table A.2 Comparison of posterior means (exogenous processes)

\begin{tabular}{|c|c|c|c|c|c|c|c|}
\hline \multirow{2}{*}{\multicolumn{2}{|c|}{$\begin{array}{r}\text { Parameters } \\
\text { Shy }\end{array}$}} & \multicolumn{2}{|l|}{$\mathrm{CZ}$} & \multicolumn{2}{|c|}{ SK } & \multicolumn{2}{|c|}{ EA } \\
\hline & & \multicolumn{6}{|c|}{ Shock persistences } \\
\hline \multirow{2}{*}{$\rho_{Y}$} & Productivity shock & 0.10 & (1) & 0.05 & $(0.5)$ & 0.07 & $(0.65)$ \\
\hline & & $(0.056)$ & [1] & $(0.026)$ & {$[0.47]$} & $(0.036)$ & {$[0.64]$} \\
\hline \multirow[t]{2}{*}{$\rho_{U I P}$} & UIP shock & 0.71 & (1) & 0.67 & $(0.94)$ & 0.76 & $(1.07)$ \\
\hline & & $(0.072)$ & [1] & $(0.067)$ & {$[0.93]$} & $(0.04)$ & {$[0.56]$} \\
\hline \multirow[t]{2}{*}{$\rho_{L O P}$} & LOP shock & 0.85 & (1) & 0.71 & $(0.84)$ & 0.82 & $(0.97)$ \\
\hline & & $(0.037)$ & [1] & $(0.076)$ & [2.07] & $(0.026)$ & {$[0.71]$} \\
\hline \multirow[t]{2}{*}{$\rho_{N W}$} & Net worth shock & 0.53 & (1) & 0.56 & $(1.07)$ & 0.43 & $(0.82)$ \\
\hline & & $(0.16)$ & {$[1]$} & $(0.14)$ & {$[0.86]$} & $(0.17)$ & {$[1.06]$} \\
\hline \multicolumn{8}{|c|}{ Shock volatilities } \\
\hline \multirow[t]{2}{*}{$\sigma_{Y}$} & Productivity shock & 3.83 & (1) & 3.80 & $(0.99)$ & 1.84 & $(0.48)$ \\
\hline & & $(1.01)$ & {$[1]$} & $(0.84)$ & {$[0.83]$} & $(0.54)$ & {$[0.53]$} \\
\hline \multirow[t]{2}{*}{$\sigma_{U I P}$} & UIP shock & 0.38 & (1) & 0.66 & $(1.71)$ & 0.42 & $(1.1)$ \\
\hline & & $(0.072)$ & {$[1]$} & $(0.102)$ & [1.42] & $(0.076)$ & {$[1.05]$} \\
\hline \multirow[t]{2}{*}{$\sigma_{L O P}$} & LOP shock & 5.10 & (1) & 4.99 & $(0.98)$ & 7.07 & (1.39) \\
\hline & & $(0.75)$ & [1] & $(0.71)$ & {$[0.94]$} & $(0.76)$ & {$[1.01]$} \\
\hline \multirow[t]{2}{*}{$\sigma_{N W}$} & Net worth shock & 1.97 & (1) & 5.89 & (2.98) & 1.58 & $(0.8)$ \\
\hline & & $(0.57)$ & [1] & $(1.53)$ & [2.69] & $(0.49)$ & {$[0.86]$} \\
\hline \multirow[t]{2}{*}{$\sigma_{M P}$} & Monetary policy shock & 0.07 & (1) & 0.24 & (3.29) & 0.07 & $(0.96)$ \\
\hline & & $(0.007)$ & [1] & $(0.027)$ & [3.62] & $(0.007)$ & {$[0.93]$} \\
\hline \multirow[t]{2}{*}{$\sigma_{y^{*}}$} & Foreign output & 0.54 & (1) & 0.53 & (1) & 0.57 & $(1.07)$ \\
\hline & & $(0.049)$ & {$[1]$} & $(0.047)$ & {$[0.97]$} & $(0.05)$ & {$[1.02]$} \\
\hline \multirow[t]{2}{*}{$\sigma_{\pi^{*}}$} & Foreign CPI inflation & 0.23 & (1) & 0.23 & (1) & 0.50 & $(2.17)$ \\
\hline & & $(0.02)$ & {$[1]$} & $(0.02)$ & {$[0.98]$} & $(0.043)$ & {$[2.14]$} \\
\hline \multirow[t]{2}{*}{$\sigma_{i^{*}}$} & Foreign interest rate & 0.05 & (1) & 0.05 & $(0.99)$ & 0.09 & $(1.69)$ \\
\hline & & $(0.005)$ & [1] & $(0.004)$ & {$[0.98]$} & $(0.008)$ & [1.67] \\
\hline
\end{tabular}

Source: authors' calculations. Notes: standard deviations in parentheses, relative to $C Z$ in brackets. 
Prior means of the foreign SVAR(1) block:

$$
\left(\begin{array}{l}
y_{t}^{*} \\
\pi_{t}^{*} \\
i_{t}^{*}
\end{array}\right)=\left(\begin{array}{ccc}
0.8 & 0 & 0 \\
0 & 0.2 & 0 \\
0 & 0 & 0.6
\end{array}\right)\left(\begin{array}{c}
y_{t-1}^{*} \\
\pi_{t-1}^{*} \\
i_{t-1}^{*}
\end{array}\right)+\left(\begin{array}{ccc}
1 & 0 & 0 \\
0.5 & 1 & 0 \\
0.3 & 0 & 1
\end{array}\right)\left(\begin{array}{c}
\varepsilon_{t}^{y^{*}} \\
\varepsilon_{t}^{\pi^{*}} \\
\varepsilon_{t}^{i^{*}}
\end{array}\right)
$$

Posterior means of the Czech model:

$$
\left(\begin{array}{c}
y_{t}^{*} \\
\pi_{t}^{*} \\
i_{t}^{*}
\end{array}\right)=\left(\begin{array}{lll}
0.90 & 0.55 & -0.50 \\
0.16 & 0.20 & -0.64 \\
0.06 & 0.06 & 0.58
\end{array}\right)\left(\begin{array}{c}
y_{t-1}^{*} \\
\pi_{t-1}^{*} \\
i_{t-1}^{*}
\end{array}\right)+\left(\begin{array}{ccc}
1 & 0 & 0 \\
0.15 & 1 & 0 \\
0.09 & -0.04 & 1
\end{array}\right)\left(\begin{array}{c}
\varepsilon_{t}^{y^{*}} \\
\varepsilon_{t}^{\pi^{*}} \\
\varepsilon_{t}^{i^{*}}
\end{array}\right)
$$

Posterior means of the Slovak model:

$$
\left(\begin{array}{l}
y_{t}^{*} \\
\pi_{t}^{*} \\
i_{t}^{*}
\end{array}\right)=\left(\begin{array}{lll}
0.89 & 0.46 & -0.63 \\
0.13 & 0.19 & -0.59 \\
0.06 & 0.05 & 0.55
\end{array}\right)\left(\begin{array}{c}
y_{t-1}^{*} \\
\pi_{t-1}^{*} \\
i_{t-1}^{*}
\end{array}\right)+\left(\begin{array}{ccc}
1 & 0 & 0 \\
0.16 & 1 & 0 \\
0.09 & -0.04 & 1
\end{array}\right)\left(\begin{array}{c}
\varepsilon_{t}^{y^{*}} \\
\varepsilon_{t}^{\pi^{*}} \\
\varepsilon_{t}^{i^{*}}
\end{array}\right)
$$

Posterior means of the model of the euro area:

$$
\left(\begin{array}{c}
y_{t}^{*} \\
\pi_{t}^{*} \\
i_{t}^{*}
\end{array}\right)=\left(\begin{array}{ccc}
0.79 & 0.14 & 0.55 \\
-0.01 & 0.18 & 0.30 \\
0.02 & -0.02 & 0.85
\end{array}\right)\left(\begin{array}{c}
y_{t-1}^{*} \\
\pi_{t-1}^{*} \\
i_{t-1}^{*}
\end{array}\right)+\left(\begin{array}{ccc}
1 & 0 & 0 \\
0.36 & 1 & 0 \\
0.09 & 0.02 & 1
\end{array}\right)\left(\begin{array}{c}
\varepsilon_{t}^{y^{*}} \\
\varepsilon_{t}^{\pi^{*}} \\
\varepsilon_{t}^{i^{*}}
\end{array}\right)
$$




\section{Appendix B}

Figure B.1 Prior and posterior densities, $\mathrm{CZ}$ (1 of 2)
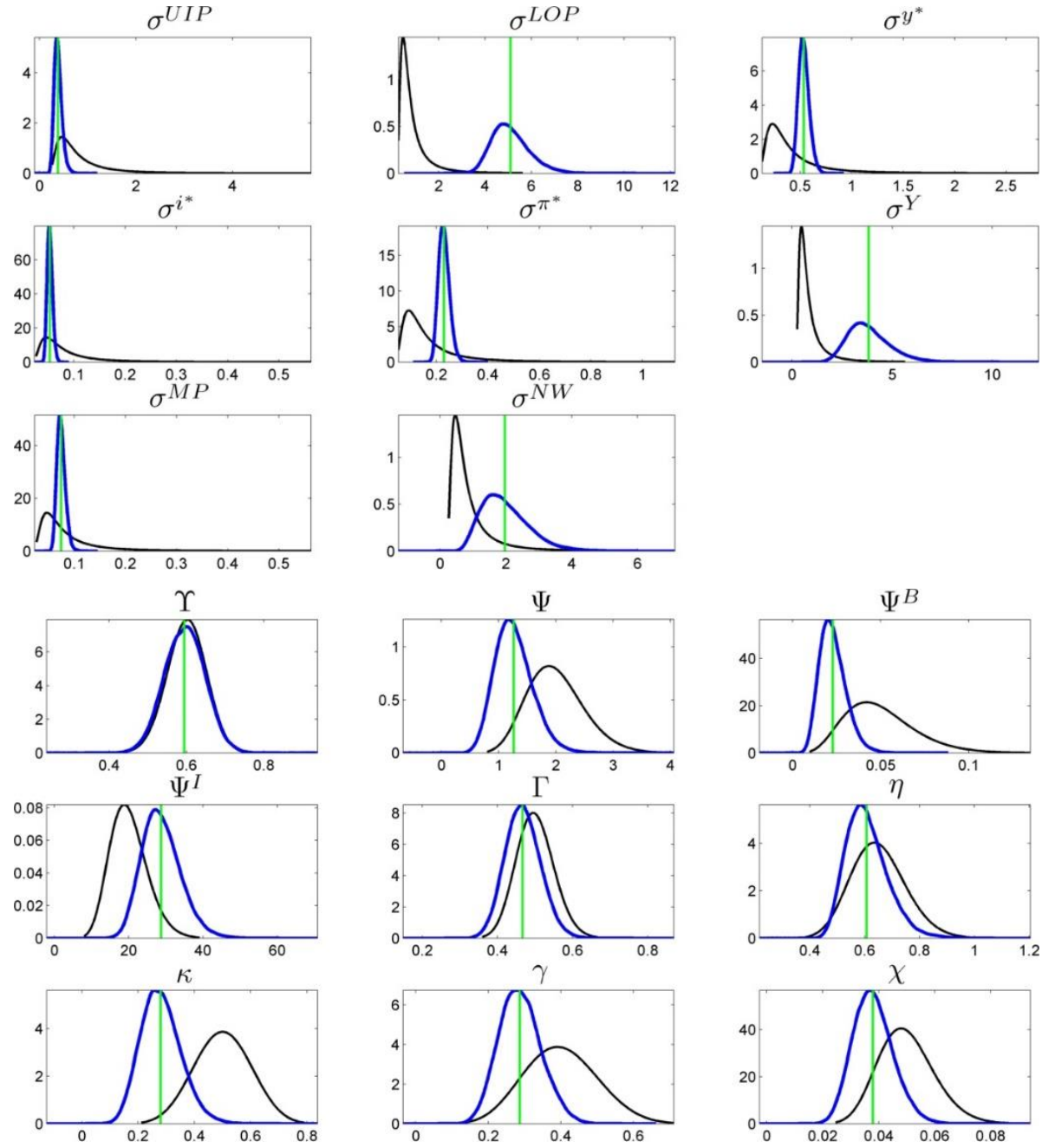

Source: authors' calculations. Note: prior distribution - black, posterior distribution - blue, posterior mode - green vertical line. 
Figure B.2 Prior and posterior densities, CZ (2 of 2)
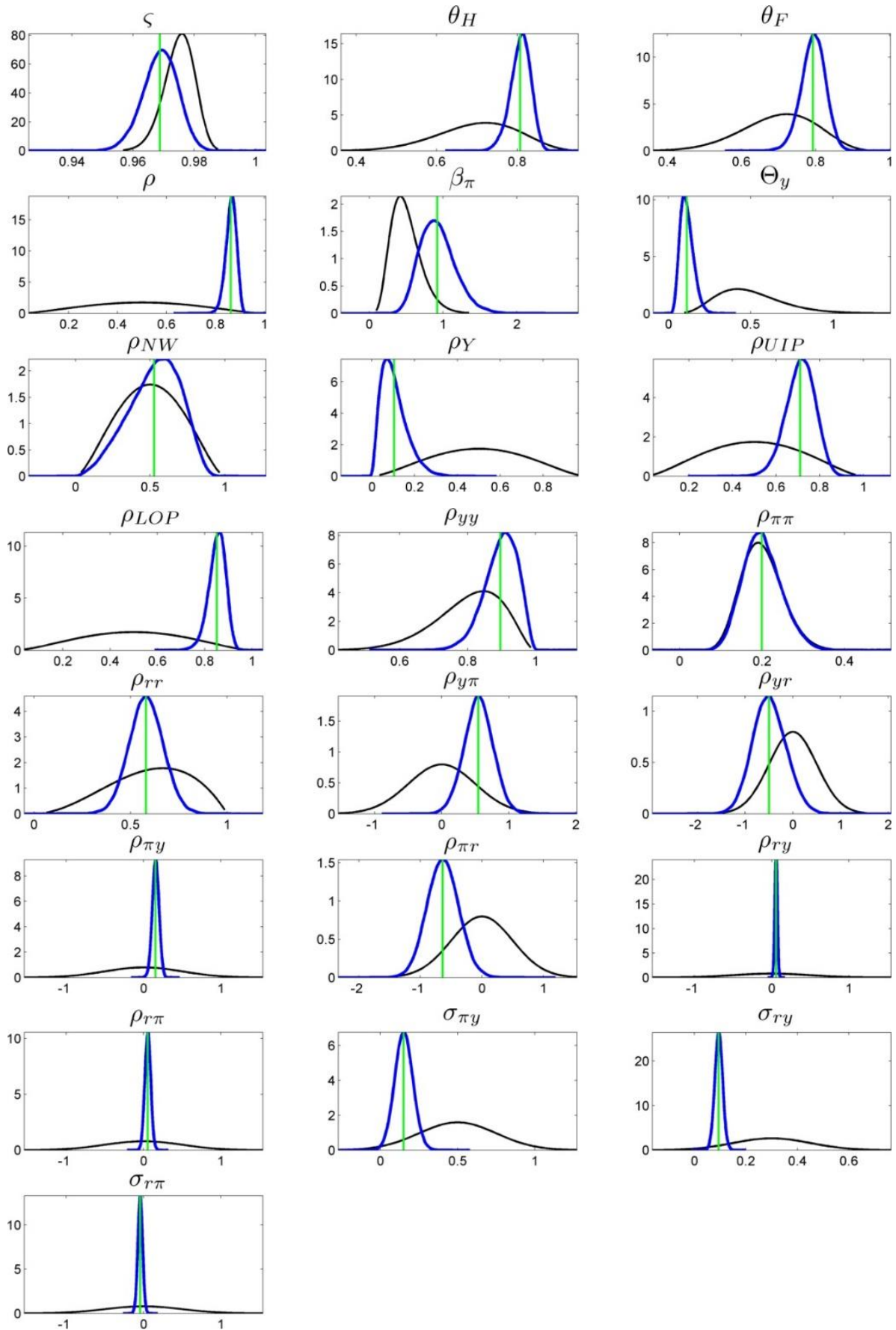

Source: authors' calculations. Note: prior distribution - grey, posterior distribution - black, posterior mode - green dashed line. 


\section{REVIEW OF ECONOMIC PERSPECTIVES}

Figure B.3 Prior and posterior densities, SK (1 of 2)
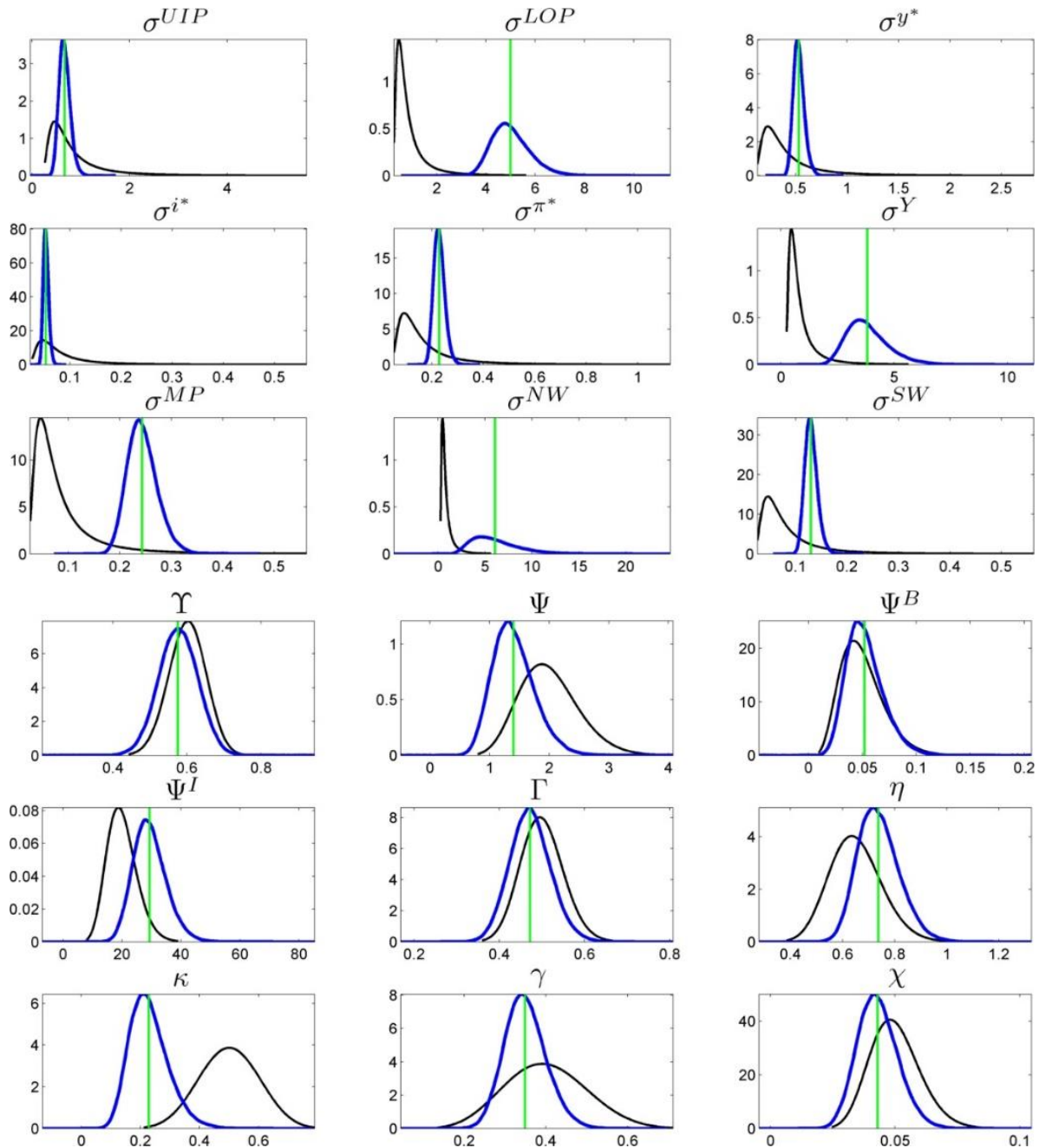

Source: authors' calculations. Note: prior distribution - grey, posterior distribution - black, posterior mode - green dashed line. 
Figure B.4 Prior and posterior densities, SK (2 of 2)
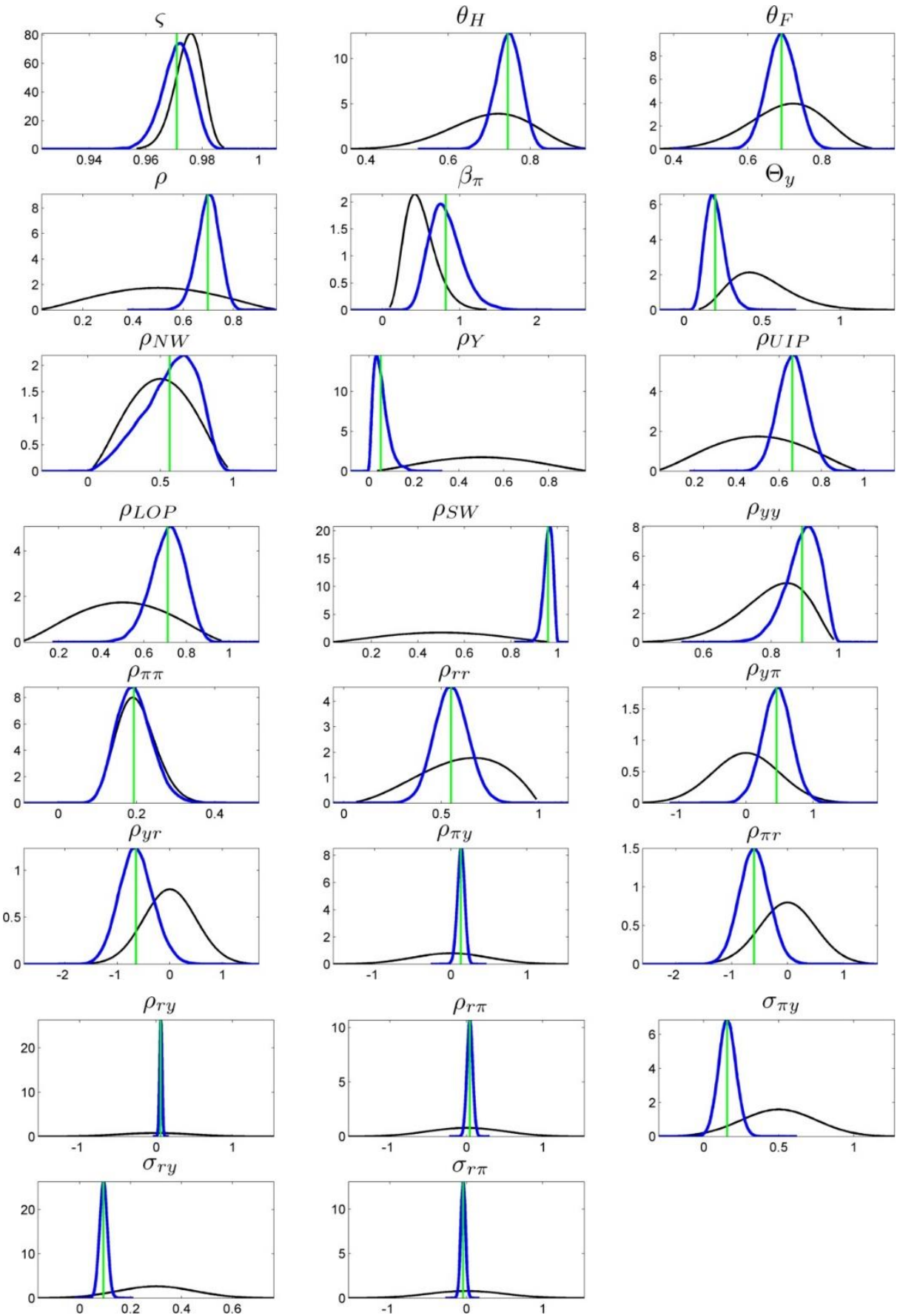

Source: authors' calculations. Note: prior distribution - grey, posterior distribution - black, posterior mode - green dashed line. 
Figure B.5 Prior and posterior densities, EA (1 of 2)
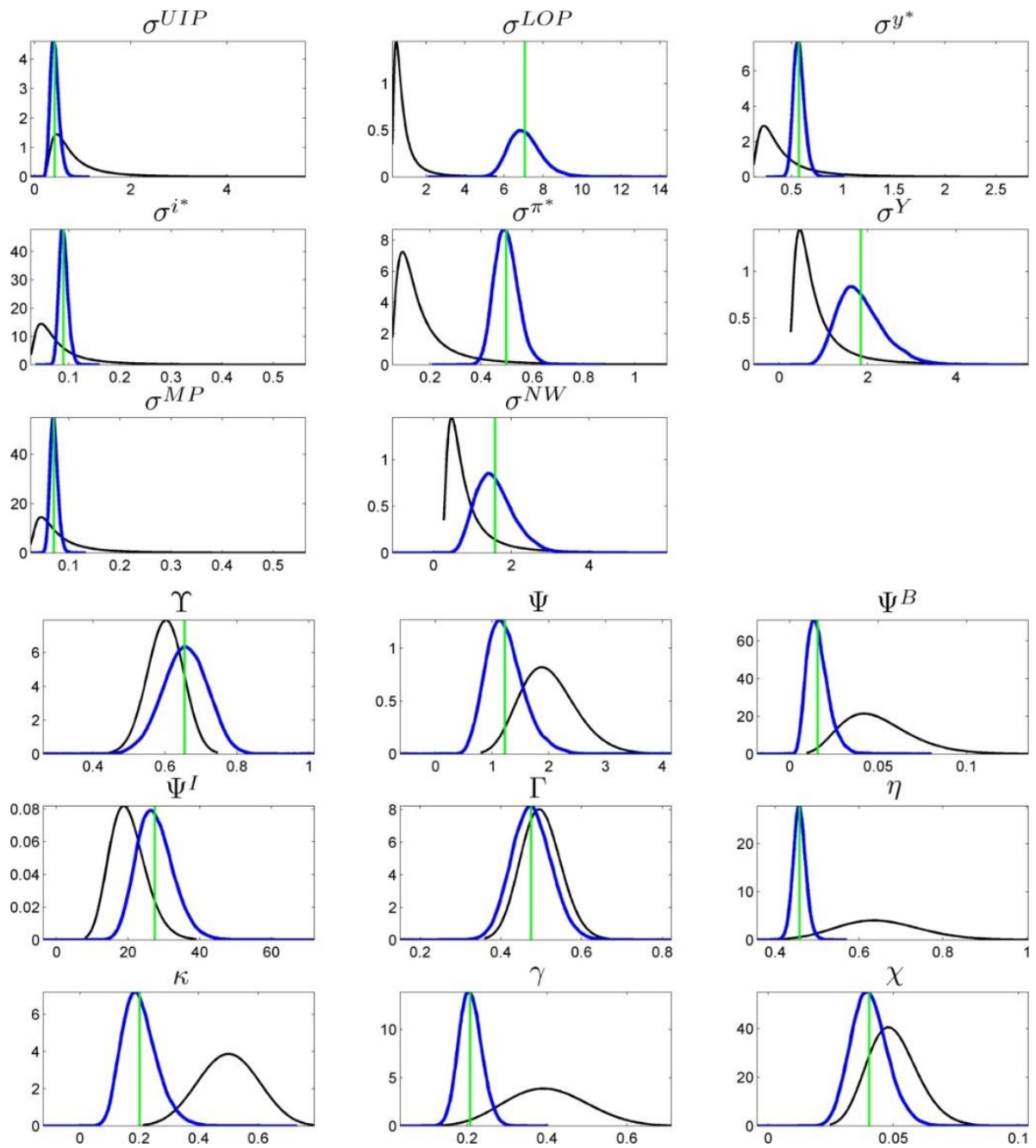

Source: authors' calculations. Note: prior distribution - grey, posterior distribution - black, posterior mode - green dashed line. 
Figure B.6 Prior and posterior densities, EA (2 of 2)
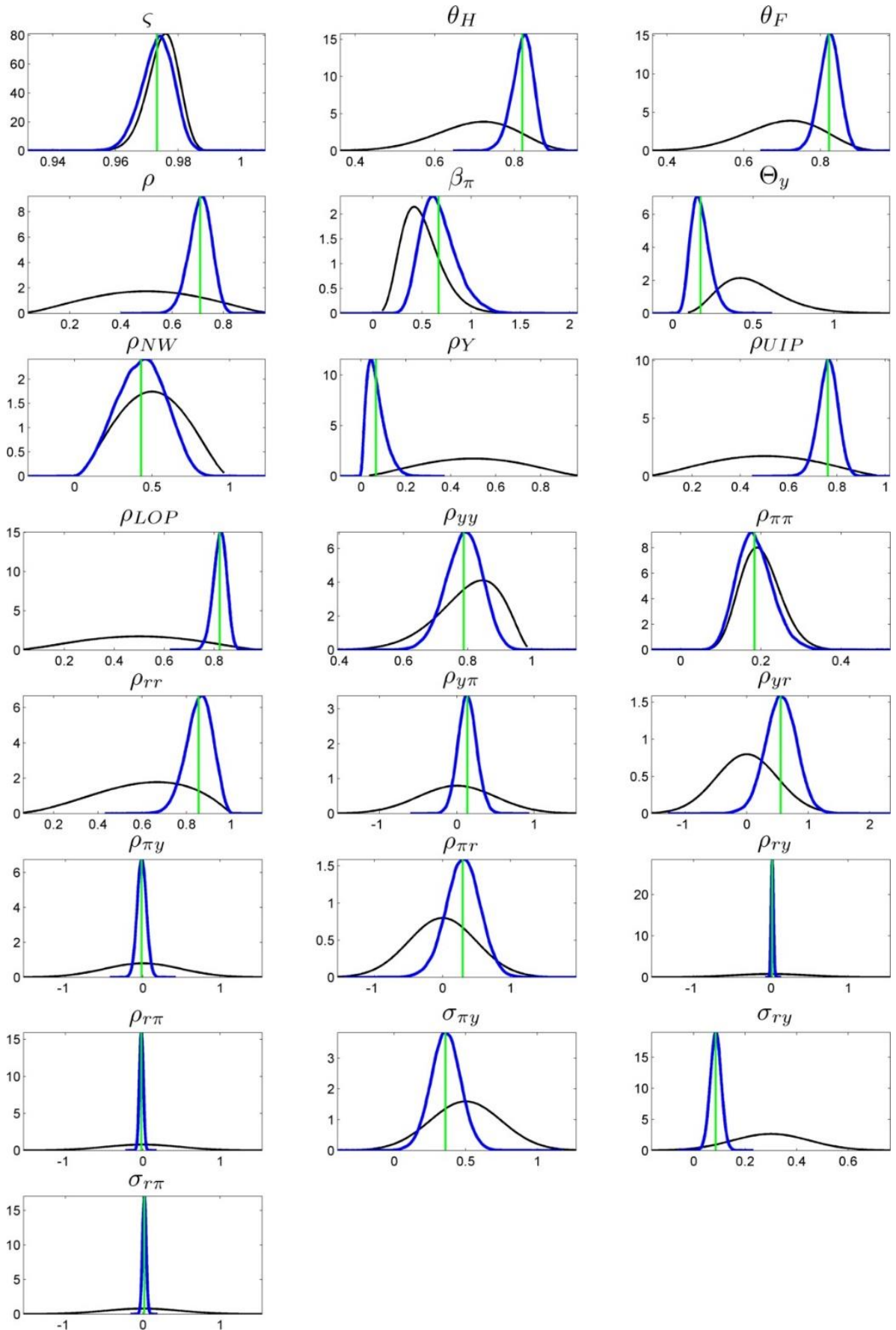

Source: authors' calculations. Note: prior distribution - grey, posterior distribution - black, posterior mode - green dashed line. 
Figure B.7 Convergence diagnostics, multivariate, $\mathrm{CZ}$
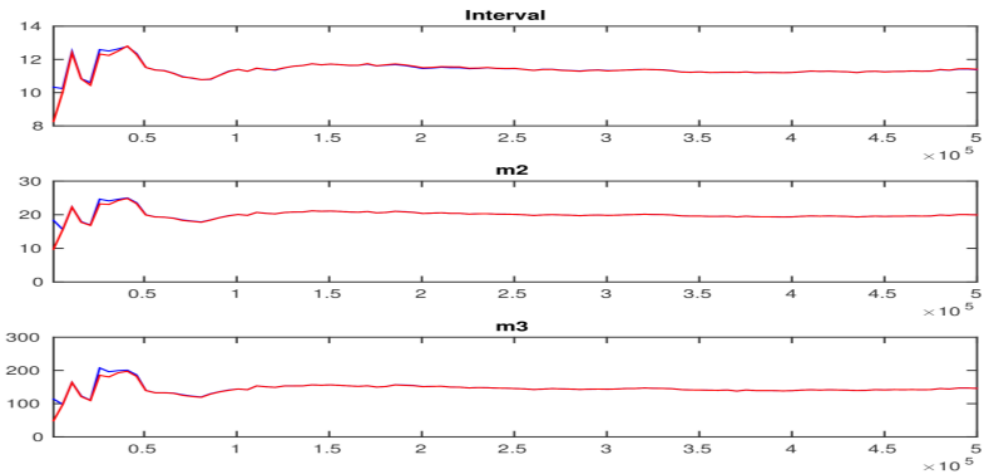

Source: authors' calculations.

Figure B.8 Convergence diagnostics, multivariate, SK
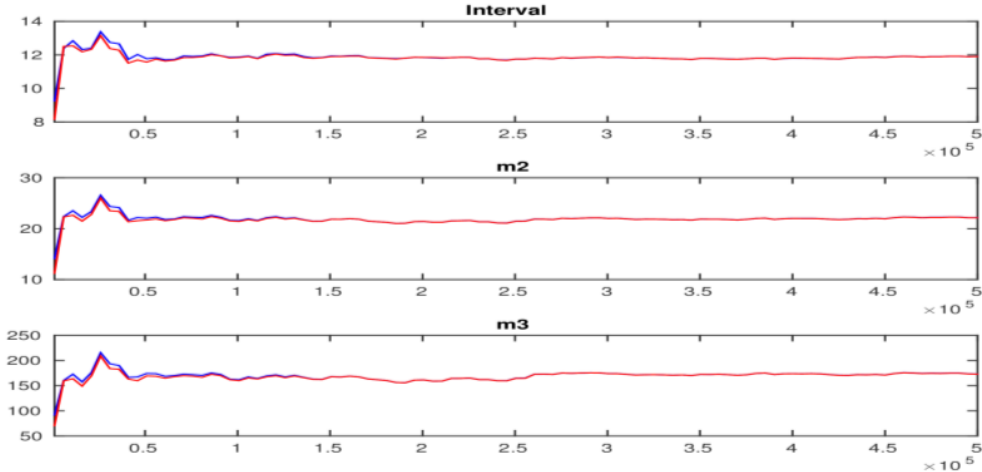

Source: authors' calculations.

Figure B.9 Convergence diagnostics, multivariate, EA
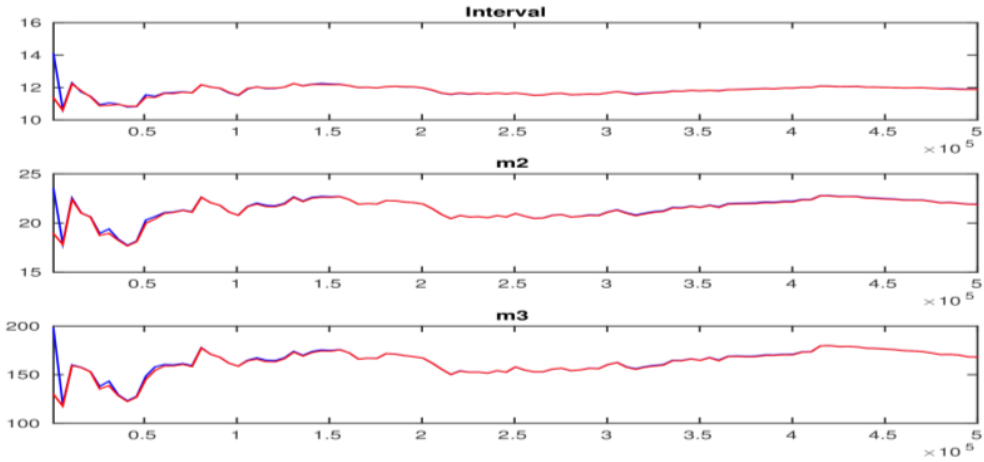

Source: authors' calculations. 